\title{
How well do integrated assessment models simulate climate change?
}

\author{
Detlef P. van Vuuren • Jason Lowe • Elke Stehfest • \\ Laila Gohar • Andries F. Hof • Chris Hope • \\ Rachel Warren • Malte Meinshausen • \\ Gian-Kasper Plattner
}

Received: 5 December 2008 / Accepted: 12 November 2009 / Published online: 11 December 2009

(C) Springer Science + Business Media B.V. 2009

\begin{abstract}
Integrated assessment models (IAMs) are regularly used to evaluate different policies of future emissions reductions. Since the global costs associated with these policies are immense, it is vital that the uncertainties in IAMs are quantified and understood. We first demonstrate the significant spread in the climate system and carbon cycle components of several contemporary IAMs. We then examine these
\end{abstract}

D. P. van Vuuren $(\varangle) \cdot$ E. Stehfest · A. F. Hof Netherlands Environmental Assessment Agency, PO Box 303, 3720 AH Bilthoven, The Netherlands e-mail: Detlef.vanvuuren@pbl.nl

J. Lowe · L. Gohar

MetOffice Hadley Centre, Exeter, UK

J. Lowe · L. Gohar

Department of Meteorology, The University of Reading, Earley Gate, Reading RG6 6BB, UK

C. Hope

Judge Business School, Cambridge University, Trumpington Street, Cambridge CB2 1AG, UK

R. Warren

Tyndall Centre, School of Environmental Sciences, University of East Anglia, Norwich NR4 7TJ, UK

M. Meinshausen

Potsdam Institute for Climate Impact Analysis,

Telegrafenberg A31, PO Box 6012 03, 14412 Potsdam, Germany

G.-K. Plattner

Environmental Physics, Institute of Biogeochemistry and Pollutant Dynamics,

ETH Zürich, Universitätstrasse 16, 8092 Zürich, Switzerland

G.-K. Plattner

Climate and Environmental Physics, Physics Institute, University of Bern,

Siedlerstrasse 5, 3012 Bern, Switzerland 
components in more detail to understand the causes of differences, comparing the results with more complex climate models and earth system models (ESMs), where available. Our results show that in most cases the outcomes of IAMs are within the range of the outcomes of complex models, but differences are large enough to matter for policy advice. There are areas where IAMs would benefit from improvements (e.g. climate sensitivity, inertia in climate response, carbon cycle feedbacks). In some cases, additional climate model experiments are needed to be able to tune some of these improvements. This will require better communication between the IAM and ESM development communities.

\section{Introduction}

Integrated Assessment Models (IAMs) have become a common tool for assessing strategies to address climate change. They aim to describe the complex relations between environmental, social and economic factors that determine future climate change and the effectiveness of climate policy, in order to derive policy-relevant insights (see e.g. Harremoes and Turner 2001; Hope 2005; Schneider 1997; Weyant et al. 1996). Policy issues addressed by IAMs include determining the costs and benefits of reducing future greenhouse gas emissions, identifying cost-effective emission reduction pathways to reach certain climate targets, investigating the type of mitigation measures required for achieving a particular target and describing the economic impacts of certain climate policies. In order to answer such questions, IAMs typically describe the cause-effect chain of climate change from economic activities and emissions to changes in climate and related impacts on e.g. ecosystems, human health and agriculture, including some of the feedbacks between these elements. As IAMs aim to integrate different disciplines, they run the risk to become extremely complex. In order to make their construction and use tractable, many IAMs use relatively simple equations to capture relevant phenomena. This simplification is most obvious for the climate system and carbon cycle, which, in many IAMs, consists of only a few equations (Goodess et al. 2003). However, the behaviour of these components can have a significant impact on IAM results and the quality of policy advice, with the possibility of simplifications in the earth system projections leading to imprecision (or even error) in projecting impacts and costs of mitigation (see also Schimel 1998; Schultz and Kasting 1997; Smith and Edmonds 2006). These simplified representations of the earth system are referred to as simple climate models (SCMs), and can be used within the IAMs or as standalone models. Often the SCMs are calibrated against more complex climate models.

As a contrast to SCMs, the most complex type of climate models are three dimensional Atmosphere-Ocean General Circulation Models (AOGCMs), which simulate the response of the atmosphere, ocean, land surface and cryosphere to a change in climate forcing, such as increases in greenhouse gas concentration. It is now technically feasible to couple AOGCMs to spatially resolved aerosol, atmospheric chemistry and carbon modules, in which case they are called Earth System Models (ESMs). Recently, there has been much interest in the interaction of the global carbon cycle with climate and therefore effort has focused on coupling Dynamic Global Vegetation Models (DGVMs, describing the global terrestrial carbon cycle and/or dynamic vegetation) to the AOGCMs. An illustration of the difference in 
complexity of ESMs versus SCMs is their computing requirements. The ESMs mostly run on supercomputers, taking anywhere from a few days to several months to simulate 100 years, while the simplest SCMs can simulate the same period on a personal computer in less than a second, albeit with much less detail. Between the SCMs and AOGCM/ESMs are Earth System Models of Intermediate Complexity (EMICs).

For EMICS, AOGCMs and ESMs regular comparisons have been made to assess their behaviour and quality (e.g. Friedlingstein et al. 2006; Meehl et al. 2007; Plattner et al. 2008; Randall et al. 2007; Sitch et al. 2008). These often reveal which variables are robustly predicted by the models, the spread of models (which provides one estimate of uncertainty in projections), and can highlight model outliers. For IAMs, such a systematic quantitative model comparison of their climate system and the carbon cycle behaviour has never been performed. A qualitative comparison has been made by Goodess et al. (2003), while some papers have looked at the climate-carbon cycle behaviour of individual IAMs. Schultz and Kasting (1997), Joos et al. (1999) and Füssel (2007), for instance, evaluated the behaviour of the DICE-1999 model with respect to simulating climate and the carbon cycle. Individual SCMs developers discuss the quality of their calibration in comparison to more sophisticated models as well (e.g. Hope 2006; Meinshausen et al. 2008). Finally, Van Vuuren et al. (2008) run selected scenarios from different IAMs through two standard climate models in order to identify uncertainty ranges.

As argued for by Schneider (1997), transparency and 'validation' tests for subcomponents are essential to ensure policy-relevance of IAMs. In this article, we systematically explore the behaviour of the climate system and carbon cycle in different IAMs and compare the outcomes to results of more complex modelsboth for individual outcomes and the overall range. We first look at the results of EMF-21, a large IAM modelling comparison exercise on multi-gas scenarios (see van Vuuren et al. 2006; Weyant et al. 2007) and demonstrate the wide spread within IAMs in linking greenhouse gas emissions to concentrations. In order to understand the reasons for differences in IAM behaviour, we then develop a set of stylised experiments for a selected set of IAMs. Since most of these experiments have also been performed by AOGCMs, ESMs or EMICs, we evaluate the behaviour of these IAMs against a selection of these more sophisticated models.

\section{Methods}

\subsection{Integrated assessment models}

The first IAMs dealing with the causes and consequences of climate change were developed in the late 1970s. Examples include models by Nordhaus (1979) and Häfele et al. (1981). These models typically only included atmospheric $\mathrm{CO}_{2}$ concentration and temperature change as environmental variables. Subsequently, IAMs were extended further and more physical detail was added (e.g. Mintzer 1987; Lashof and Tirpack 1989; Rotmans et al. 1990). Since then, a large number of such models have been developed (see also Schneider (1997) for an overview of the development history). In 2002, van der Sluijs (2002) listed more than 50 climate change IAMs. Over the last decade, some IAMs have expanded their coverage in terms of land use 
and terrestrial carbon cycle representation, non- $\mathrm{CO}_{2}$ gases and air pollutants and by looking into specific impacts of climate change (e.g. water and human health). IAMs can be distinguished in different categories (Goodess et al. 2003; van Vuuren et al. 2006). Some IAMs have a stronger focus on economics, such as multi-sectoral computable general equilibrium models that are combined with climate modules and models focussed on cost-benefit analysis. Other IAMs are more focussed on the physical processes in both the natural system and the economy (integrated structural models/biophysical impact models).

The degree of simplification of the carbon cycle and climate system depends on the purpose of the model (Goodess et al. 2003). In IAMs focussing on costbenefit analysis (e.g. DICE, FUND and MERGE (see Table 1) the carbon cycle and climate system are often strongly simplified. Typically, the fate of atmospheric $\mathrm{CO}_{2}$ is a function of the emission or concentration level, while the fate of non$\mathrm{CO}_{2}$ greenhouse gases is given by a box model with constant life times. Resulting concentrations are directly used to calculate radiative forcing. Next, changes in equilibrium temperature are derived from changes in radiative forcing, and a simple delay function is typically used to estimate transient temperature change. IAMs focussing more on physical processes typically have more detail in the representation of climate and carbon cycle. In fact, most of these IAMs use an upwelling-diffusion energy balance model in combination with a representation of the global carbon cycle (e.g. MAGICC) to describe both the fate of greenhouse gases and climate change at a global scale. Additionally, changes in global climate are sometimes downscaled to provide grid-scale climate parameters, which can be used as an input to drive grid level agricultural growth models. Going beyond that some IAMs include a detailed description of the terrestrial carbon pools at a grid scale, thereby incorporating some of the complex feedbacks between climate, carbon cycle, land cover and land use [e.g. IMAGE (Bouwman et al. 2006)]. In some cases, IAMs are even directly coupled to an EMIC [e.g. MIT IGSM (Sokolov et al. 2005)].

\subsection{EMF-21 comparison}

In EMF-21, a total of 18 modelling groups collaborated in developing a set of multigas scenarios (see van Vuuren et al. 2006; Weyant et al. 2007). The model groups were asked to submit a model preference baseline and two scenarios aiming at stabilising radiative forcing at $4.5 \mathrm{~W} / \mathrm{m}^{2}$ between 2100 and 2150 (targeting all gases and $\mathrm{CO}_{2}$-only). The fact that all participating IAMs developed stabilisation scenarios for the same target allows for an interesting comparison of the implications of different representations of atmospheric chemistry, the carbon cycle and the climate system.

We run the reported emissions of 11 models (using only those models that covered at least $\mathrm{CO}_{2}, \mathrm{~N}_{2} \mathrm{O}, \mathrm{CH}_{4}$ ) in MAGICC-4 (Wigley and Raper 2001). The choice of MAGICC is not critically important for our purpose here: what matters is that the greenhouse gas emissions from the different IAMs are applied to the same SCM. Even though the emission pathways of the IAMs differ (as a result of differences in assumed mitigation costs, reduction constraints etc), they should all - by definition lead to a radiative forcing near $4.5 \mathrm{~W} / \mathrm{m}^{2}$ within the original IAM. If running the emission paths of the different IAMs in one standard climate model (i.e. MAGICC) leads to very different radiative forcing levels, this be indicative of differences in 


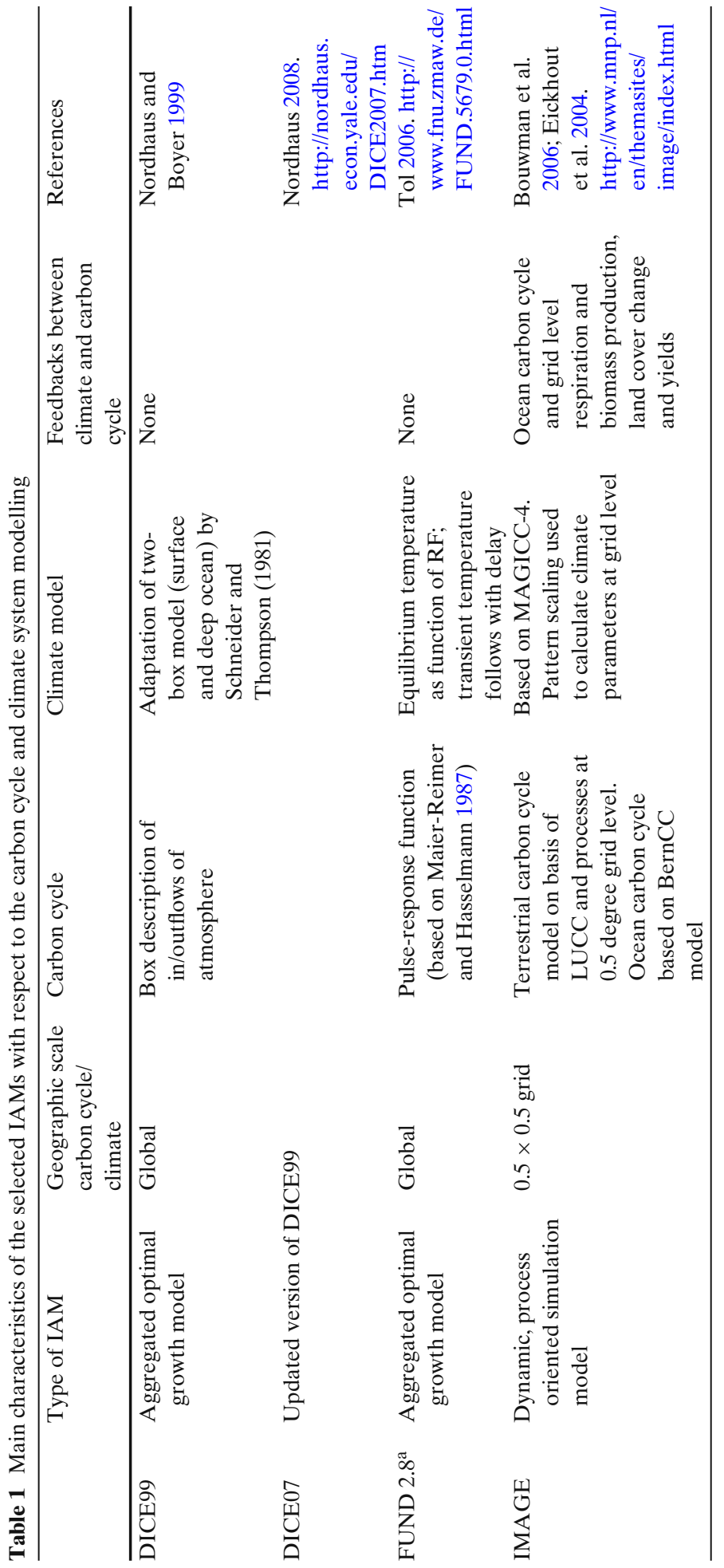




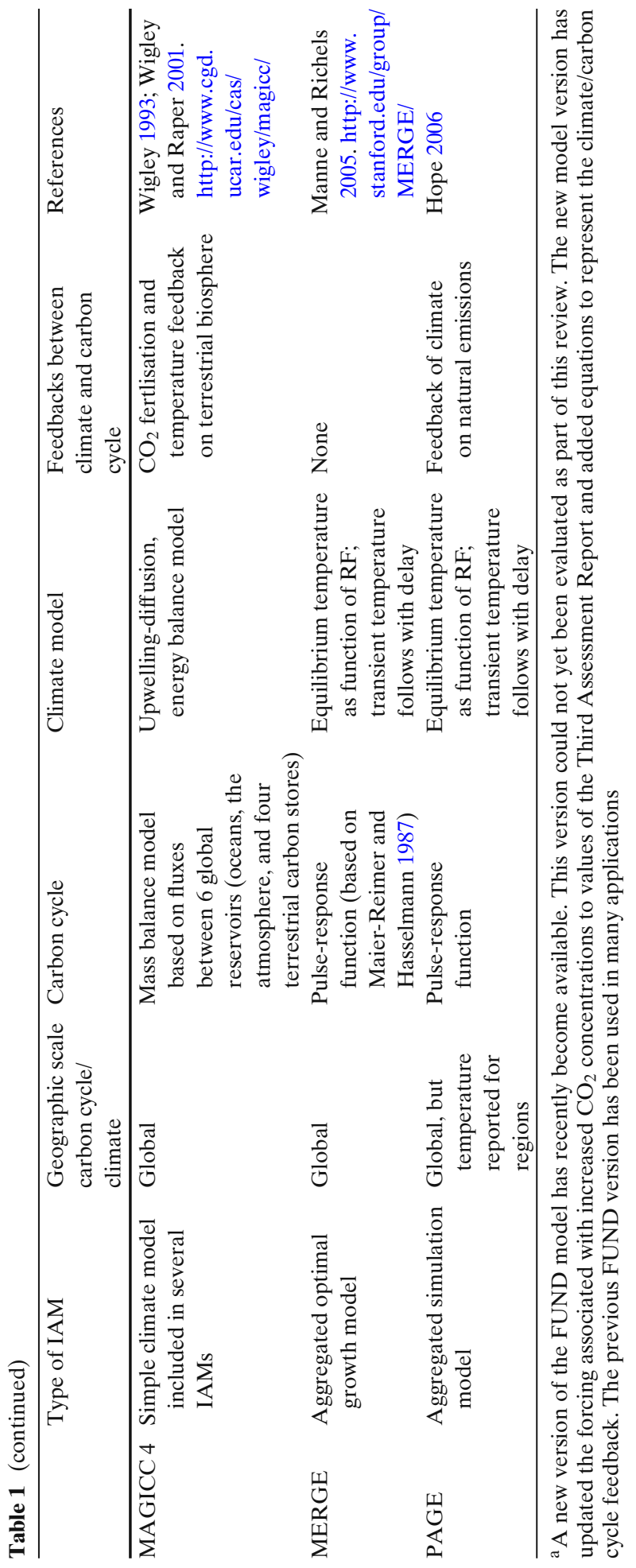


the atmospheric chemistry, carbon cycle and climate parts of these IAMs. The experiment thus allows us to compare a large range of models, but it does not provide much insight into the underlying causes of differences.

The key climate parameters within MAGICC are set to the median values from the Met Office Hadley Centre derived probability distribution functions of the climate sensitivity (based on Murphy et al. 2004) (i.e. $3.2^{\circ} \mathrm{C}$ ), the ocean diffusivity (based on IPCC 2001) and the carbon cycle climate feedback parameter (based on a fit of the outcomes of Friedlingstein et al. (2006)). The MAGICC model is driven by observed greenhouse gas concentrations up to 1999 and by the emissions from the EMF-21 models from 2000 onwards. It should also be noted that not all of the 11 IAMs provided emissions data for halocarbons and air pollutants (including sulphur and $\mathrm{NO}_{x}$ ) (five models had some missing emissions data). Here, the average emissions from the six IAMs without missing data were used to replace missing emissions data in the remaining simulations. As in most IAMs, these forcing categories are small in 2100 (van Vuuren et al. 2006), it is expected that this has only a small impact on our main conclusions (but diverging results of the five IAMs with missing data could be partly explained by this).

\subsection{Detailed comparison}

The second set of experiments focussed on the detailed behaviour of selected IAMs. Specifically, we tried to answer the following questions:

1. What is the equilibrium temperature level for a particular stabilisation of radiative forcing?

2. What is the transient temperature response before temperature stabilisation is reached?

3. How does radiative forcing respond to changes in $\mathrm{CO}_{2}$ concentration?

4. How does the carbon cycle behave (including feedbacks), i.e. what is the relationship between $\mathrm{CO}_{2}$ emissions and $\mathrm{CO}_{2}$ concentration?

5. What is the overall model behaviour under a high emission scenario?

6. What is the overall model behaviour under a stringent overshoot mitigation scenario?

These questions more-or-less follow the causal chain from emissions to concentration to radiative forcing to temperature change in a reversed order and have been used to structure the paper. For reasons of simplification, we have decided to focus solely on $\mathrm{CO}_{2}$ emissions, thus leaving the concentration of all other gases at their pre-industrial values. We have selected a group of IAMs for these experiments. The IAMs were selected based on their wide application in policy-relevant assessments and on their availability to include them in these experiments. These IAMs are DICE99, DICE07, FUND, IMAGE, MERGE, PAGE and the SCM MAGICC-4 (see Table 1 for a brief description and references). While MAGICC is not strictly an IAM, it is used within many more complex IAMs to model the carbon cycle and climate system, including MiniCam (Edmonds et al. 2004), MESSAGE (Riahi et al. 2007) and CIAS (Warren et al. 2008) In the comparison, we used the MAGICC-4 model (Wigley and Raper 2001) that uses the same settings as applied in the Third Assessment Report. The IMAGE model uses MAGICC-4 for its climate system model-which implies that 
some of the results presented in this paper are identical for IMAGE and MAGICC4-but uses its own carbon cycle model. For DICE, an updated version has recently become available (DICE07). However, as the DICE99 version has been applied frequently over the last few years and was also included earlier in evaluations of climate and carbon cycle behaviour of IAMs, we have also used this older version. For PAGE, in most graphs the $5 \%$, mean and $95 \%$ outcomes are shown because the PAGE model results are usually presented in a probabilistic way.

In order to answer the questions raised above, the following stylised experiments were run for all IAMs listed in Table 1:

(a) Step increase in radiative forcing. An instantaneous increase of radiative forcing was introduced to a level corresponding to doubling of the pre-industrial $\mathrm{CO}_{2}$ concentration $\left(3.7 \mathrm{~W} / \mathrm{m}^{2}\right)$, recording the change in global mean temperature. The experiment provides insight into the climate sensitivity of the different models (question 1), and in the temporal development of temperature change (question 2) under an instantaneous increase in forcing.

(b) $1 \%$ annual increase in $\mathrm{CO}_{2}$ concentration $\left(2 \times \mathrm{CO}_{2}\right.$ experiment). The $\mathrm{CO}_{2}$ concentration was increased by $1 \%$ annually starting from pre-industrial levels in year zero (using 1860 concentration). After 70 years, when a doubling is reached, concentrations were held constant. This experiment is run regularly for complex climate models (Randall et al. 2007). We use this experiment to analyse the transient temperature response (question 2). Additionally, this experiment is used to examine the relationship between $\mathrm{CO}_{2}$ concentration and radiative forcing as included in the IAMs (question 3).

(c) $\mathrm{CO}_{2}$ decay. In this experiment, a short term $\mathrm{CO}_{2}$ emission pulse was introduced in year zero that instantaneously leads to a doubling of the $\mathrm{CO}_{2}$ concentration in the atmosphere. The subsequent time evolution of atmospheric $\mathrm{CO}_{2}$ concentration was recorded. This experiment provides insight into the overall behaviour of the carbon cycle (question 4). This experiment has been run in the past with more complex carbon cycle models (e.g. Hooss et al. 2001; Joos et al. 1996; Maier-Reimer and Hasselmann 1987).

(d) High $\mathrm{CO}_{2}$ emissions. In this experiment, $\mathrm{CO}_{2}$ emissions followed a historic trajectory from 1860-2000 and the SRES A2 baseline from 2000-2100 (Nakicenovic 2000). After 2100, emissions were held constant until 2200 (see Fig. 1). All other forcings are kept at pre-industrial levels. The experiment is done in two modes: (1) the carbon cycle reacts to elevated $\mathrm{CO}_{2}$ concentrations and to changes in temperature and precipitation and therefore the natural feedbacks between atmosphere, ocean, vegetation and changing climate are included (coupled mode) and (2) the climate feedbacks (temperature and precipitation) are switched off (uncoupled). ${ }^{1}$ The experiment is similar to the C4MIP experiments (Friedlingstein et al. 2006).

\footnotetext{
${ }^{1}$ Most of the IAMs included in this comparison do not include a climate (temperature or precipitation) effect on the carbon flows between ocean, atmosphere and vegetation. Therefore this difference is only important for IMAGE, MAGICC and PAGE.
} 
Fig. $1 \mathrm{CO}_{2}$ emission trajectories for experiments $\mathrm{d}$ and e, following the IPCC A2 scenario (Nakicenovic 2000) and a stringent overshoot mitigation scenario aimed at stabilising greenhouse gases at 450 ppm $\mathrm{CO}_{2}$-eq. (Lowe et al. 2009a) (E1) (in both cases emissions are held constant after 2100)

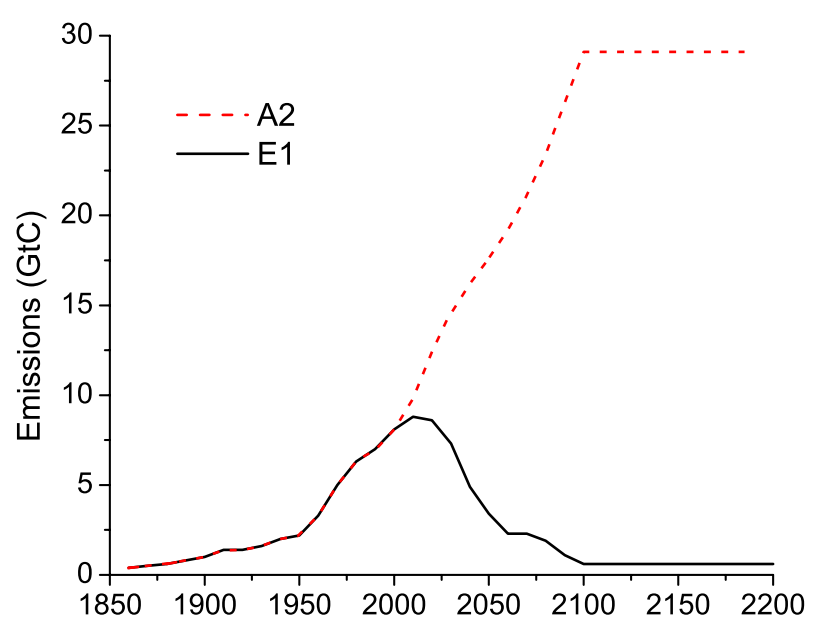

(e) Low $\mathrm{CO}_{2}$ emissions scenario. This experiment is similar to experiment d, but $\mathrm{CO}_{2}$ emissions after 2000 followed a mitigation scenario aimed at stabilising greenhouse gas concentrations at 450 ppm $\mathrm{CO}_{2}$-eq. (Fig. 1). This scenario had been developed by the IMAGE model for the ENSEMBLES project, and is subsequently called E1 (Lowe et al. 2009a). ${ }^{2}$ As in experiment d, "coupled" and "uncoupled" simulations were also performed where possible.

Experiments $\mathrm{d}$ and e are used to assess the feedbacks between climate and carbon cycle, by comparing results from the coupled and uncoupled mode as in C4MIP (question 4) (see for more detail the results section). Additionally, they are used to investigate the overall climate response of the IAMs under a high emission scenario (question 5) and a stringent overshoot mitigation scenario (question 6). Experiments $\mathrm{d}$ and e closely correspond to the experimental design of the new scenario development for IPCC (Moss et al. 2008) which envisions that the information from the complex climate models is compared to and fed back into the original IAM scenarios. In that context, the results of this paper are also directly relevant for the new IPCC exercise.

Throughout our analysis, we compare our results with those from more complex models. For experiment a, b and d (up to 2100), direct information was available from IPCC-AR4 (Randall et al. 2007) and the C4MIP model comparison (Friedlingstein et al. 2006). For the other experiments, we used dedicated "expert model" runs (the term expert model refers here to models that have a more elaborate representation of the relevant dynamics than IAMs and are compared on a regular basis to other sophisticated models in the field). For experiment $\mathrm{c}$, we have used new model runs of

\footnotetext{
${ }^{2}$ The E1 scenario is derived from an implementation of the A1 baseline. In terms of development of emissions and the most important reduction categories, it is comparable to earlier scenarios developed using the IMAGE model derived from the B2 baseline. A detailed description of those scenarios can be found in Van Vuuren et al. (2007). For the purpose of this article, only the emission trajectory is relevant.
} 
the Bern2.5CC model. This model is a reduced complexity climate model (Plattner et al. 2008) that especially includes a detailed description of the carbon cycle. For the low emissions scenario experiment e, no direct information for comparison was available. Therefore, we have run the Hadley model HADSCCCM1 (Huntingford et al. 2009) and the MAGICC 6.0 model (Meinshausen et al. 2008) for comparison. Both are simple global average climate models that have been calibrated to the C4MIP results. This allows an indirect comparison of the IAM model runs and C4MIP. In Appendix A, we show the performance of both models against the original C4MIP dataset, indicating that for the original A2 run, both models indeed are able to reproduce the behaviour of the full C4MIP set. Further research, however, is being conducted to confirm whether the calibration of these simple models is still valid at low concentration levels and for overshoot scenarios (Lowe et al. 2009a).

\section{Do differences in climate system and carbon cycle representation of IAM model matter?}

The MAGICC-4 results for the $4.5 \mathrm{~W} / \mathrm{m}^{2}$ stabilisation runs of 11 IAMs selected from the EMF-21 study are shown in Fig. 2 (as indicated in the method section, the MAGICC-4 version as applied in this paragraph is run with MetOffice medium parameter settings). While the emission trajectories reportedly lead to stabilisation at $4.5 \mathrm{~W} / \mathrm{m}^{2}$ in the corresponding IAM (with its specific carbon cycle and climate representations), running them in the MAGICC-4 model may not necessarily lead to a similar forcing. These differences in forcing are (at least partly) indicative of the importance of different representations of the carbon cycle and climate system in different IAMs. The results show that most models end up in MAGICC-4 the results near the $4.5 \mathrm{~W} / \mathrm{m}^{2}$ target. Still, the spread of the models with "comparable" behaviour is up to $0.5 \mathrm{~W} / \mathrm{m}^{2}$. The models AIM, COMBAT and FUND show larger differences. In the case of AIM, the difference can be explained by a different trajectory for sulphur than in most other models (higher emissions and less reduction under climate policy) (see Table 2). For COMBAT and FUND, the differences are caused by significantly different $\mathrm{CO}_{2}$ emissions compared to other models (high in COMBAT and low in FUND). Consequently, the $\mathrm{CO}_{2}$ concentration and total radiative forcing for COMBAT are the highest of all the models, while FUND has the lowest $\mathrm{CO}_{2}$ concentrations and one of the lowest forcings (Fig. 2). The corresponding temperature change in this MAGICC-4 model (with a climate sensitivity of $3.2^{\circ} \mathrm{C}$ ) follows the radiative forcing trajectories; the majority of models reach a value of $2.5^{\circ} \mathrm{C}$ and $3^{\circ} \mathrm{C}$ by 2100 . The results suggest that there are considerable differences among IAMs, and the experiments in the next sections will assess in more detail where these differences lie.

\section{Detailed comparison of carbon cycle and climate system representation in IAM models}

\subsection{What is the equilibrium temperature response?}

An important variable that is used to describe the temperature increase as a result of an increase in greenhouse gas concentration in the atmosphere is the so-called 

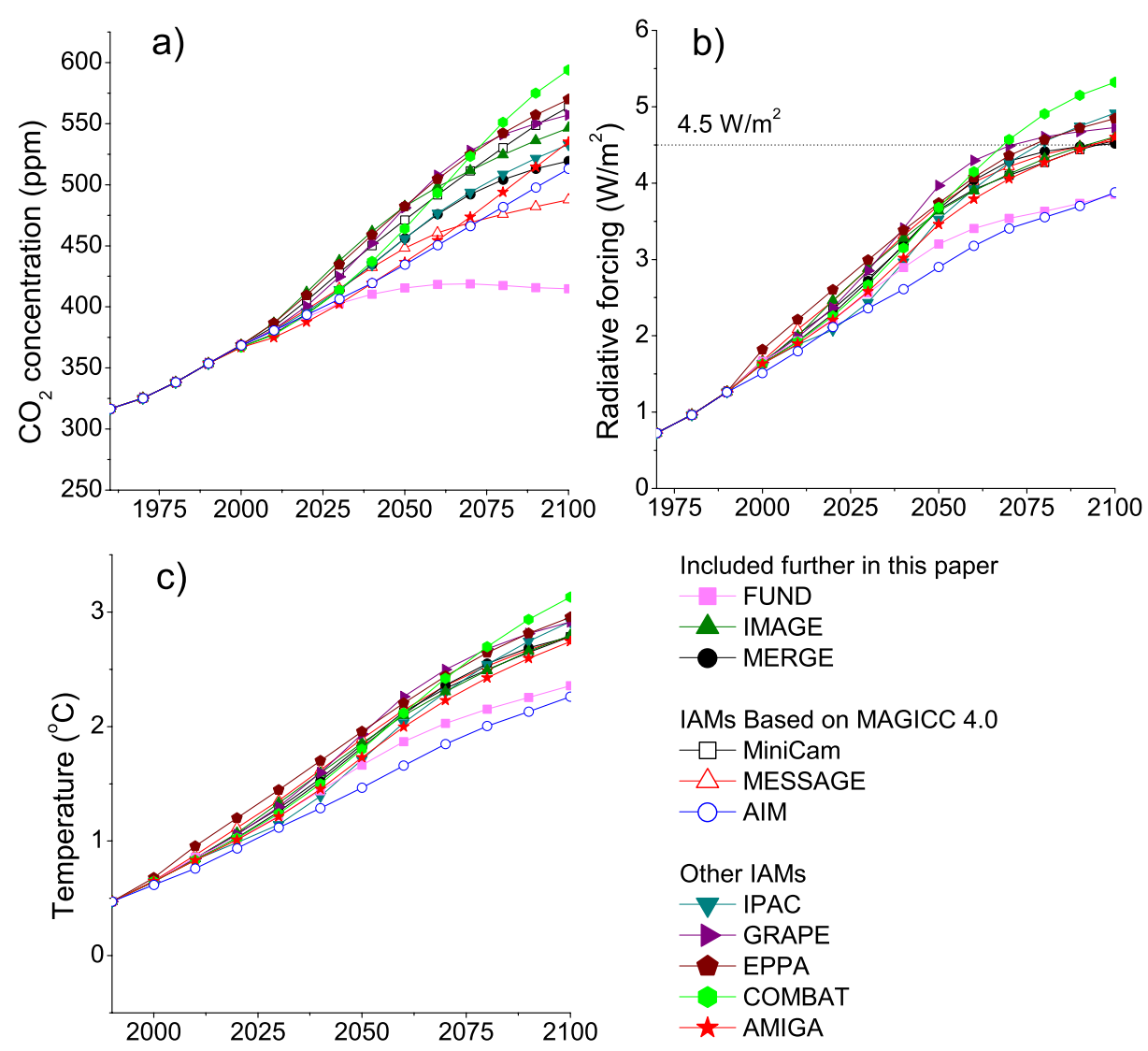

Included further in this paper

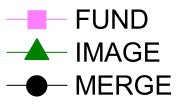

IAMs Based on MAGICC 4.0
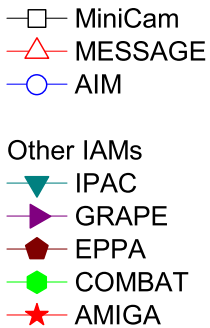

Fig. 2 MAGICC-4 outcomes for the EMF-21 emission trajectories aiming at stabilization at $4.5 \mathrm{~W} / \mathrm{m}^{2}$ as reported by Weyant et al. (2007): a $\mathrm{CO}_{2}$ concentration, b radiative forcing and c temperature

climate sensitivity. It is commonly defined as the equilibrium change in global mean temperature $\left(\Delta \mathrm{T}_{2 \mathrm{x}}\right)$ that results from a radiative forcing $\left(\Delta \mathrm{F}_{2 \mathrm{x}}\right)$ corresponding to a doubling of atmospheric $\mathrm{CO}_{2}$ concentration. The equilibrium climate sensitivity

Table 2 MAGICC-4 results for radiative forcing and relative contribution of halocarbons and sulphur (S) in 2100 using the EMF-21 emissions data

\begin{tabular}{|c|c|c|c|c|c|}
\hline \multirow[t]{2}{*}{ Model } & \multicolumn{3}{|c|}{ Radiative forcing $\left(\mathrm{Wm}^{-2}\right)$} & \multicolumn{2}{|l|}{ Ratios } \\
\hline & $\begin{array}{l}\Sigma\left(\mathrm{CO}_{2},\right. \\
\left.\mathrm{CH}_{4}, \mathrm{~N}_{2} \mathrm{O}\right)\end{array}$ & $\Sigma$ Halocarbon & $\Sigma S$ & $\begin{array}{l}\Sigma \text { Halocarbon/ } \\
\Sigma\left(\mathrm{CO}_{2}, \mathrm{CH}_{4}, \mathrm{~N}_{2} \mathrm{O}\right) \\
(\%)\end{array}$ & $\begin{array}{l}\Sigma \mathrm{S} / \Sigma\left(\mathrm{CO}_{2},\right. \\
\left.\mathrm{CH}_{4}, \mathrm{~N}_{2} \mathrm{O}\right) \\
(\%)\end{array}$ \\
\hline AIM & 4.178 & 0.152 & -0.837 & 4 & -20 \\
\hline EPPA & 4.789 & 0.129 & -0.974 & 3 & -20 \\
\hline IPAC & 4.409 & 0.505 & -0.416 & 11 & -9 \\
\hline IMAGE & 4.383 & 0.224 & -0.240 & 5 & -5 \\
\hline MESSAGE & 4.372 & 0.232 & -0.530 & 5 & -12 \\
\hline MiniCAM & 4.325 & 0.226 & -0.282 & 5 & -7 \\
\hline
\end{tabular}

Only models that all greenhouse gas species into account have been included 
Fig. 3 Temperature increase for an instantaneous increase of radiative forcing to $3.7 \mathrm{~W} / \mathrm{m}^{2}$ (experiment a; introduced in year 50). The likely range of climate sensitivity reported by IPCC Fourth Assessment Report (Meehl et al. 2007) is added for comparison

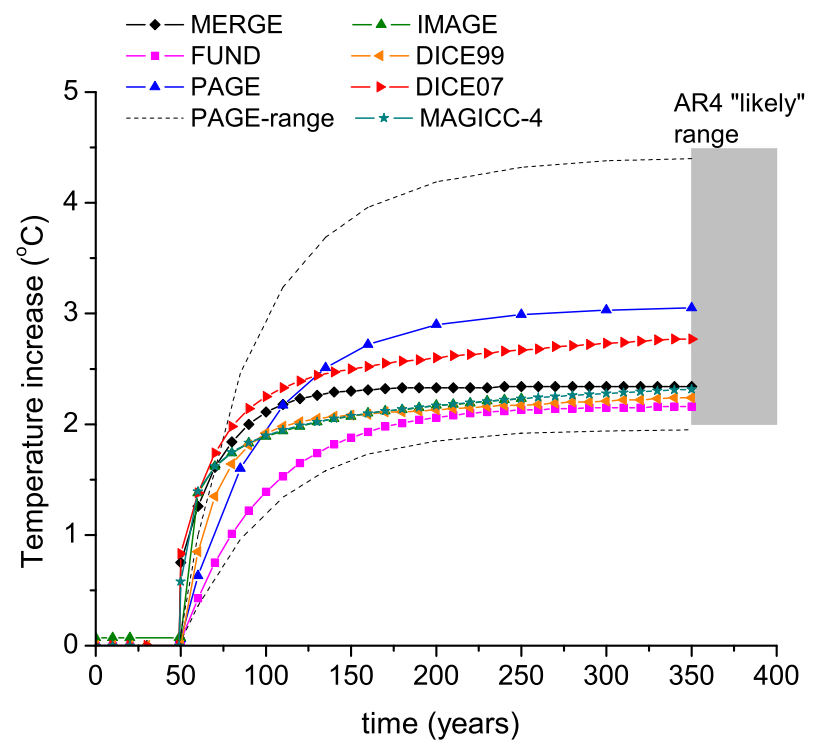

$\Delta T_{2 x}=\Delta F_{2 x} / \alpha$ is inversely proportional to $\alpha$, where $\alpha$ is a measure of the strength of the feedback processes in the system. The equilibrium climate sensitivity is a straightforward, aggregated measure of how the climate responds to an increase in radiative forcing and is in fact used to calibrate SCMs. In 3D AOGCMs the climate sensitivity is not prescribed, it is an emergent property of the model. According to the IPCC's fourth assessment report, the likely range of climate sensitivity is between $2^{\circ} \mathrm{C}$ and $4.5^{\circ} \mathrm{C}$ (and very likely to be above $1.5^{\circ} \mathrm{C}$, while values above $4.5^{\circ} \mathrm{C}$ cannot be ruled out), and $\Delta \mathrm{F}_{2 \mathrm{x}}$ approximately equal to $3.7 \mathrm{~W} / \mathrm{m}^{2}$ (Meehl et al. 2007).

As described above (Section 2.3, experiment a), we apply an instantaneous increase to a forcing of $3.7 \mathrm{~W} / \mathrm{m}^{2}$ to all IAMs, and record the simulated temperature over a period of 300 years (Fig. 3). As all models use climate sensitivity as an explicit model input, the comparison between this (reported) parameter and the temperature change after 300 years shows that by this time all but the slowest responding models have come close to a new equilibrium temperature (Table 3 ).

Table 3 Comparison of reported climate sensitivity, the temperature increase after 300 years in response to a $3.7 \mathrm{~W} / \mathrm{m}^{2}$ forcing, and the ratio between the 100 year and 300 year response (as a measure of how fast the equilibrium temperature is reached)

\begin{tabular}{llll}
\hline Model & $\begin{array}{l}\text { Reported CS } \\
\left({ }^{\circ} \mathrm{C}\right)\end{array}$ & $\begin{array}{l}\text { T-3.7 (300 years) } \\
\left({ }^{\circ} \mathrm{C}\right)\end{array}$ & $\begin{array}{l}\text { T-3.7 (100 years/300 years) } \\
(-)\end{array}$ \\
\hline DICE99 & 2.9 (check) & 2.24 & 0.93 \\
DICE07 & 3.0 & 2.77 & 0.90 \\
FUND & 2.5 & 2.16 & 0.87 \\
IMAGE & 2.5 & $(2.31)$ & \\
MAGICC-4 & 2.5 & 2.31 & 0.90 \\
MERGE & 2.5 & 2.34 & 0.98 \\
PAGE (mean) & 3.0 & 3.05 & 0.86 \\
\hline
\end{tabular}


In all IAMs, climate sensitivity is an exogenous model parameter, and the reported values used in their standard set-up are indicated in Table 3. The climate models of FUND, MERGE, DICE and PAGE consists of two simple equations: (1) relating the change in radiative forcing $(\Delta \mathrm{F})$ to a change in temperature $(\Delta \mathrm{T})$ on the basis of climate sensitivity as described above, and (2) a fixed delay between actual and equilibrium temperature. This is equivalent to assuming that all heat added to the ocean is trapped in a single well mixed layer. MAGICC-4 contains a far more complex description of heat transfers between different atmosphere and ocean layers.

The temperature increase of DICE07 and PAGE (mean) approaches $3^{\circ} \mathrm{C}$ in 2200 , which is consistent with the most likely value for climate sensitivity reported in the IPCC's Fourth Assessment Report (Meehl et al. 2007). The outcomes of the other models cluster around $2.2-2.3^{\circ} \mathrm{C}$, largely determined by an exogenously set value for climate sensitivity of $2.5^{\circ} \mathrm{C}$ [based on the common interpretation as a median value reported in IPCC's Third Assessment Report (Wigley and Raper 2001)]. This implies that the long-term temperature increase of all IAMs are within the sizeable uncertainty range for equilibrium temperature increase reported currently by IPCC - but many of them are in the lower part of this range. Specifically for FUND, it can be added that the 2200 warming of $2.2^{\circ} \mathrm{C}$ in this experiment is caused by the fact that this model assumes the forcing for a $\mathrm{CO}_{2}$ doubling to be $4.3 \mathrm{~W} / \mathrm{m}^{2}$ (and not $3.7 \mathrm{~W} / \mathrm{m}^{2}$ ). In the equation used in FUND to calculate the equilibrium warming $\left(\Delta \mathrm{T}_{\mathrm{eq}}=\Delta \mathrm{F}_{\mathrm{eq}} / \Delta \mathrm{F}_{2 \mathrm{x}} \times \Delta \mathrm{T}_{2 \mathrm{x}}\right)$, the model divides the exogenously set forcing of $3.7 \mathrm{~W} / \mathrm{m}^{2}$ by the expected forcing for a $\mathrm{CO}_{2}$ doubling, resulting in a lower temperature increase than expected by the climate sensitivity (see also Section 4.3 for more details).

\subsection{What is the transient temperature response?}

For climate policy, the transient climate response is arguably as important as the equilibrium response. This is in particular the case for so-called overshoot scenarios with a peak in radiative forcing level (to avoid short-term stringent reductions) followed by a decline later on (den Elzen and Van Vuuren 2007; Huntingford and Lowe 2007) (see also Section 4.7). Due to the slow response of the climate system, the equilibrium temperature corresponding to the peak in radiative forcing is never reached. Additionally, not the equilibrium temperature, but the actual temperature in each time step determines the impacts in IAMs. In cost-benefits analyses (for which IAMs are often used) usually some form of discounting is applied: a financial flow in the future is given less value than the same financial flow today. An important reason for this is that current finance can be invested, creating an (expected) positive return. Moreover, as future societies are likely to be richer, the same amount of money is also simply assumed to be less valuable to them. The mechanism of discounting is a crucial factor in an optimal balance between the costs and benefits of climate policy, making the timing of temperature increase (and thus financial damages) very relevant (Hof et al. 2008). If the equilibrium temperature level is reached only slowly, this will lead to a lower damage estimate than if the same temperature increase is reached earlier in time. The rate of temperature change (i.e. the transient temperature change) depends on all the interacting processes that affect energy input, output, and storage in the ocean. 
Useful information on the transient warming response times of the IAMs and SCMs can be extracted from the step increase in forcing experiment (Section 4.1). However, rather than the final temperature, we now focus on the rate at which the final temperature is approached (Fig. 3). The response time varies across models, from a very rapid response in MERGE to a slow response in FUND and PAGE. The results of the DICE are most comparable to MAGICC-4, but with a slower initial response. The same information can also be illustrated by calculating the 100 year warming as fraction of the 300 year warming (Table 3). It should be noted that the response of some models cannot be precisely explained by a single time constant. For instance, the MAGICC-4 model (and thus also IMAGE) shows a rapid early response, but a much slower eventual response approaching equilibrium. The results of DICE are most comparable to MAGICC-4, but with a slower initial response. The initial PAGE response is slower than many of the other IAMs, but, partly due to the higher climate sensitivity, it has the largest warming after about 100 years (Table 3 ).

An alternative way to characterise the time evolution of warming is using the socalled transient climate response (TCR), which is defined as the temperature increase after 70 years of a scenario with a $1 \%$ compound increase in $\mathrm{CO}_{2}$ concentrations per year, starting from pre-industrial. This measure is particularly useful as more AOGCMs have run the $1 \%$ experiment than the step forcing experiment. The range of TCR values serves to illustrate differences in model response. Figure 4 shows these results of the IAM experiments and compares the results with those reported in IPCC's AR4 (Randall et al. 2007) (for these, the 10th-90th percentiles are shown, as well as the mean).

We observe that the spread in AOGCM temperatures increases during the period of increasing forcing, and remains approximately constant when forcing is stabilised. Most IAMs remain within the variation of results for the more complex AOGCMs.
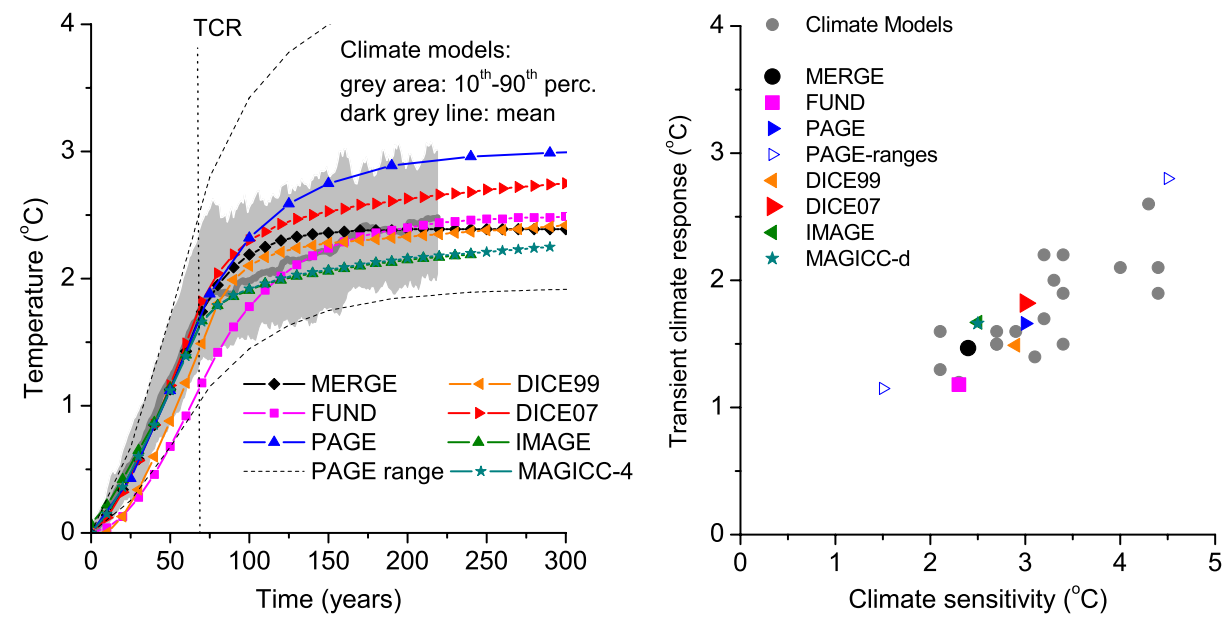

Fig. 4 Results for experiment $\mathrm{b}$, with an annual $1 \%$ increase in $\mathrm{CO}_{2}$ concentration (starting from 1860 concentration), followed by constant concentration after doubling has been reached. Temperature as a function of time (left) and climate sensitivity versus transient climate response (TCR) (right). The TCR equals the temperature change increase at the time reaching the constant concentration. Climate model results from Randall et al. (2007) 
The mean result from PAGE is on the high end of the range of the climate model outcomes after 100-150 years, but has a medium outcome in the preceding period, consistent with the step forcing experiment (the 5-95\% percentile follow the ranges of the AOGCMs at first, but later, the high end of the PAGE range ends up considerably higher than this range). The response in DICE99 and especially FUND is slower than that of the comprehensive models included in the IPCC AR4 range. As both models are run often for cost-benefit analysis, this is a crucial finding, as it delays eventual impacts further into the future, implying that these are therefore discounted more strongly. Thus, compared to a faster response of similar eventual warming, a cost minimisation calculation will conclude that there is less need for abatement or adaptation. In DICE07, the earlier DICE99 response time has already been corrected, allowing a significantly more rapid response. The MAGICC-4 model (and thus the IMAGE model) are characterised by a relatively rapid short-term response, but by a moderate long-term response. Interestingly, in the complex climate models, there seems to be a more noticeable change in trajectory of temperature increase once the equilibrium concentration is reached (around year 70) than in many of the IAMs. This AOGCM behaviour is also noticeable in MAGICC-4 and may be due to multiple ocean layers. The slow response times in some IAMs also suggest that they would not be suitable for looking at rapid radiative forcing changes (such as e.g. associated with volcanic forcing).

\subsection{What is relationship between greenhouse gas concentration and radiative forcing?}

In the IAMs, the link between greenhouse gas concentration and climate change is not only determined by the climate response to an increase in radiative forcing, but also by the increase in radiative forcing as a function of concentrations. The relationship between the $\mathrm{CO}_{2}$ concentration and corresponding radiative forcing is in all IAMs defined by a logarithmic, expressed as $\mathrm{RF}=\mathrm{a} \times \ln \left(\mathrm{CO}_{2} / \mathrm{CO}_{2, \text { ref }}\right)$ (Fig. 5). However, the value of the constants, a and $\mathrm{CO}_{2}$,ref varies between models. Reference

Fig. 5 Radiative forcing versus concentration increase (grey area indicates the main value and suggested uncertainty interval from the IPCC's Third Assessment Report, i.e. plus/minus $10 \%$ ) (Ramaswamy 2001)

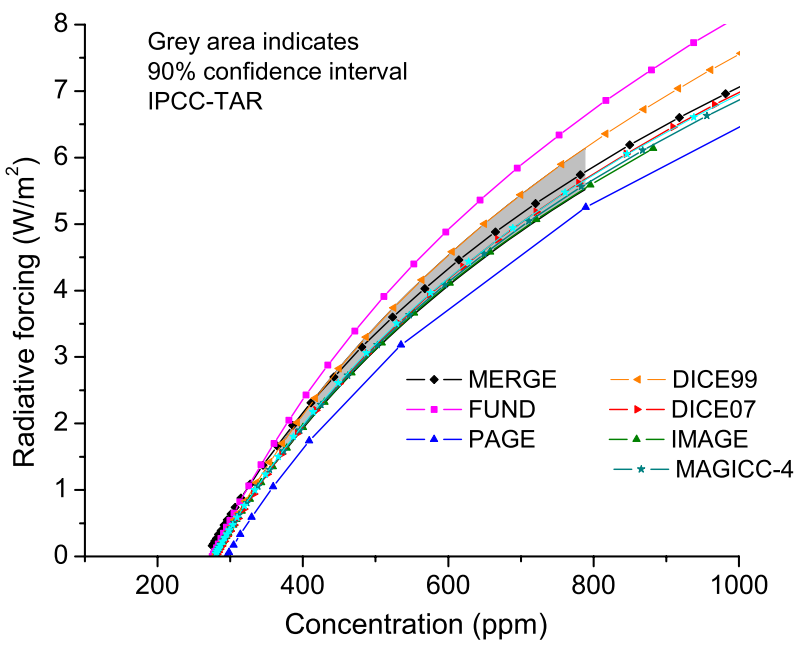


values from IPCC's third assessment report lead to a value $3.7 \mathrm{~W} / \mathrm{m}^{2}$ for a doubling of the $\mathrm{CO}_{2}$ concentration (Ramaswamy 2001). The value for "a" in MAGICC-4, IMAGE, MERGE, DICE07 and PAGE are all based on this value and therefore, these models all cluster together in Fig. 5. The $\mathrm{CO}_{2} /$ radiative forcing curves of FUND and DICE99 form outliers on the high side, while the PAGE model has a slightly lower forcing (Fig. 5). In the case of FUND, this is caused by the fact that it uses parameters derived from IPCC's First Assessment Report (Shine et al. 1990), which at that time assigned a considerably higher forcing level to $\mathrm{CO}_{2}\left(4.3 \mathrm{~W} / \mathrm{m}^{2}\right.$ for a doubling of the concentration). The difference between FUND and the other models is in fact considerable. At a $\mathrm{CO}_{2}$ concentration of $650 \mathrm{ppm}$, the difference in forcing between FUND and the cluster of models is $0.7 \mathrm{~W} / \mathrm{m}^{2}$ (Fig. 5). This is also the cause of lower $\mathrm{CO}_{2}$ a concentration in FUND in Fig. 2. In order to arrive at the $4.5 \mathrm{~W} / \mathrm{m}^{2}$ target, based on the older $\mathrm{CO}_{2}$ forcing factor, FUND has to reach a $\mathrm{CO}_{2}$ concentration of around $575 \mathrm{ppm}$ instead of $650 \mathrm{ppm}$ - thus also requiring much lower emissions than other models. It should, however, be noted that in FUND the equilibrium temperature response is defined by the climate sensitivity divided by the same $\mathrm{CO}_{2}$ forcing factor. As a result, variations in forcing and climate sensitivity compensate each other if the models are run on the basis of emission trajectories or temperature targets (which is their usual mode of operation).

\subsection{How does the carbon cycle behave?}

Thus far, we have looked at how IAMs calculate the amount of warming for a certain increase in forcing, and how they determine radiative forcing from a given increase in atmospheric $\mathrm{CO}_{2}$ concentration. Another crucial step in the causal chain from emissions to temperatured change is to calculate the atmospheric $\mathrm{CO}_{2}$ concentration as a function of emissions. At present, about $50 \%$ of the anthropogenic $\mathrm{CO}_{2}$ emissions are rapidly taken up by the terrestrial biosphere and the ocean. During the past decade, a number of complex model studies have suggested that the airborne fraction, i.e. the amount of annual anthropogenic $\mathrm{CO}_{2}$ emissions remaining in the atmosphere, might increase in future due to climate change (Cox et al. 2000; Friedlingstein et al. 2006).

A common way to characterise the response of carbon cycle models is to put a single large pulse of emissions into the atmosphere and monitor the simulated decline over time as the carbon is transferred from the atmosphere to the natural carbon reservoirs in the terrestrial biosphere and the ocean. Complex carbon cycle models show that, after an initial rapid decline, the rate of removal is limited by the carbonate chemistry in the ocean leaving about $20 \%$ of the original $\mathrm{CO}_{2}$ airborne until it is finally stored in deep sediments (millennia time scale). The feedbacks with climate change can further complicate the rate of decline.

In DICE, MAGICC-4 and IMAGE, the carbon cycle is represented by different carbon pools with representative exchange rates (with increasing complexity from the simple DICE model to several terrestrial carbon pools in each $0.5 \times 0.5$ grid cell in IMAGE). Both IMAGE and MAGICC-4 also explicitly represent carbon uptake by the ocean and terrestrial biosphere (see also Table 1). PAGE, MERGE and FUND represent the carbon cycle by a simple impulse-response function. The functions of MERGE and FUND are based on Maier-Reimer and Hasselmann (1987). The functions of Maier-Reimer and Hasselmann (that are calibrated to a single coupled 
atmosphere-ocean coupled model) consist of five integrals, each of which having a typical exponential decay time and receiving a certain fraction of the emissions. Three sets of parameters are provided for a pulse emission that increases the carbon dioxide concentration to $1.25 \times, 2 \times$ and $4 \times$ the pre-industrial $\mathrm{CO}_{2}$ concentration $\left(\mathrm{CO}_{2}\right.$ pre-ind $)$, respectively. The parameters for the first two experiments lie close together, while the third set has some significant changes (and thus behaviour, leading to a higher net response time). In fact, this implies that the carbon response can not be represented precisely over a range of different concentrations by one single impulse model. The MERGE model uses the parameters derived from the $1.25 \times \mathrm{CO}_{2}$ pre-ind pulse, while FUND uses the parameters corresponding to the $2 \times$ $\mathrm{CO}_{2}$ pre-ind pulse. The pulse-response function in PAGE only includes one exponential decay time, in combination with a fraction of the emissions that is removed immediately.

Our first experiment for exploring the carbon cycle representation in IAMs uses an instantaneous pulse emission resulting in a doubling or quadrupling of the preindustrial $\mathrm{CO}_{2}$ concentration. While the experiment was performed in the past for AOGCMs and EMICs (e.g. Hooss et al. 2001; Joos et al. 1996; Maier-Reimer and Hasselmann 1987), here, we use dedicated runs of the Bern2.5CC EMIC as point of reference for a more complex carbon cycle representation. We also compare results with the results of the MAGICC- 6 model, which has recently been calibrated against the C4MIP outcomes. The left part of Fig. 6 shows the fraction of $\mathrm{CO}_{2}$ remaining airborne in the 'doubling' experiment, while the right part shows the airborne fraction after 'quadrupling' compared to fraction after 'doubling'. As the carbon cycle in PAGE is strongly influenced by climate feedbacks, both PAGE and the reference model Bern2.5CC were run with (COU) and without (UNC) climate feedbacks on the carbon cycle.
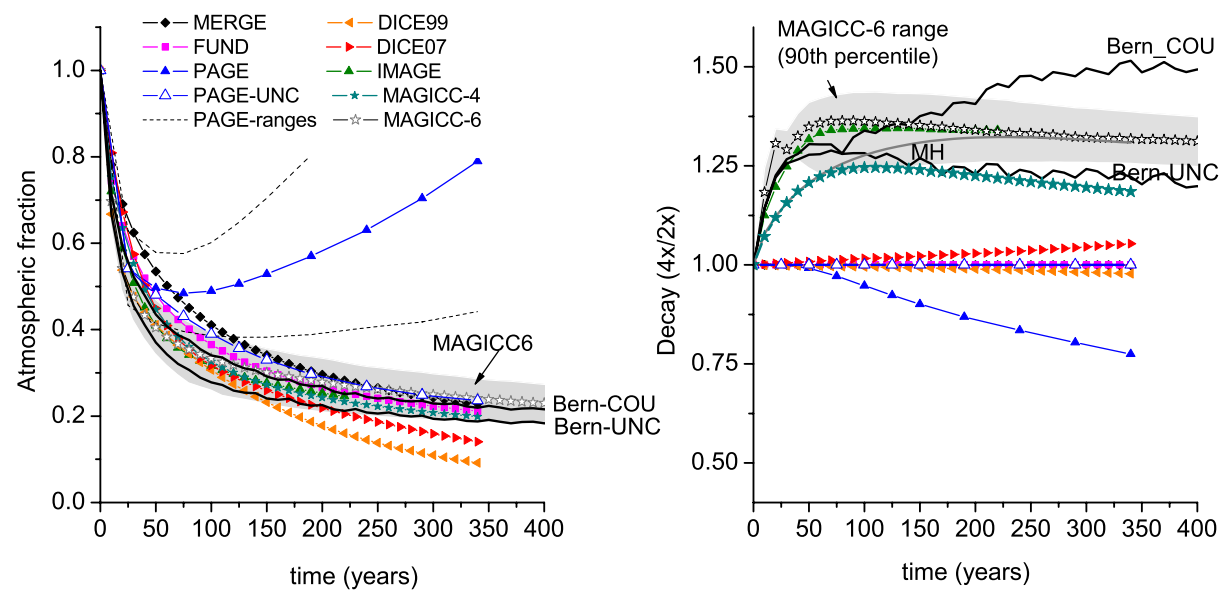

Fig. 6 Fraction of $\mathrm{CO}_{2}$ remaining in the atmosphere after a pulse emission in 1860 that leads to a doubling of pre-industrial $\mathrm{CO}_{2}$ concentration (left) and the ratio between the atmospheric fraction for a pulse leading to quadrupling and doubling of concentration (right) (UNC indicates a model run without climate feedbacks for PAGE and Bern2.5CC); MAGICC-6 (grey area), Bern2.5CC and MH (Maier-Reimer and Hasselmann) added as references for comparison 
Table 4 Fraction of $\mathrm{CO}_{2}$ remaining in the atmosphere after a pulse emission that leads to a doubling of pre-industrial $\mathrm{CO}_{2}$ concentration

The abbreviations COU and UNC refer to the experiments with (COU) and without (UNC) climate-carbon cycle feedbacks

\begin{tabular}{lllll}
\hline & \multicolumn{4}{l}{ Time period after pulse } \\
\cline { 2 - 5 } & $50 \mathrm{yr}$ & $100 \mathrm{yr}$ & $150 \mathrm{yr}$ & $300 \mathrm{yr}$ \\
\hline MERGE & 0.53 & 0.41 & 0.34 & 0.24 \\
FUND & 0.48 & 0.37 & 0.30 & 0.22 \\
PAGE-COU & 0.50 & 0.49 & 0.53 & 0.70 \\
PAGE-UNC & 0.48 & 0.39 & 0.33 & 0.25 \\
IMAGE & 0.41 & 0.32 & 0.28 & \\
DICE99 & 0.41 & 0.31 & 0.23 & 0.11 \\
DICE07 & 0.45 & 0.32 & 0.26 & 0.16 \\
MAGICC-4 & 0.41 & 0.32 & 0.29 & 0.24 \\
Bern2.5CC-COU & 0.44 & 0.34 & 0.29 & 0.23 \\
Bern2.5CC-UNC & 0.37 & 0.28 & 0.24 & 0.19 \\
\hline
\end{tabular}

The results show that the "doubling" pulse emission (left part of Fig. 6 and Table 4) leads to a relatively rapid decay in DICE99 and (in the long run) DICE07, a somewhat slow decay (in the first 200 years) in MERGE, and a behaviour in PAGE that is clearly different than that of the expert models. All other models compare well to the results of the Bern2.5CC model and the range resulting from the C4MIP calibrated MAGICC-6 model. The results for the DICE99 model were discussed earlier in detail by Joos et al. (1999). They described the very rapid decay in DICE99 as "neglecting first-order physical principles and conflicting with models used in the carbon cycle community". The DICE07 model has a slower decay although after 150 years still clearly faster than the Bern2.5CC (reference) results. For PAGE, the runs with the climate carbon cycle feedback first shows the typical decrease for the atmospheric $\mathrm{CO}_{2}$ concentration, but the concentration increases again after about 100 years. That is caused by the "carbon cycle feedback" in PAGE being represented by a temperature dependent natural emission factor (see further in the article a comparison of this feedback to more complex models). The magnitude of the feedback in PAGE is much larger than in the Bern2.5CC reference model. The mean result from the PAGE model run with the feedback switched off (labelled at PAGE-U in Fig. 6) complies closely with the more complex carbon cycle models.

The rate of $\mathrm{CO}_{2}$ removal from the atmosphere depends on the $\mathrm{CO}_{2}$ concentration due to non-linearities in the ocean inorganic carbon chemistry: the higher the total amount of inorganic carbon in the ocean, the lower the capacity of the ocean to take up additional $\mathrm{CO}_{2}$ from the atmosphere [an effect know as the Revelle or Buffer factor of the ocean (Revelle and Suess 1957)]. This means that at higher atmospheric $\mathrm{CO}_{2}$, the relative rate of $\mathrm{CO}_{2}$ removal by the ocean is reduced. This is shown on the right side of Fig. 6 by the higher atmospheric fraction for the quadrupling experiment compared to the doubling experiment for the Bern 2.5CC model, MAGICC-6 model and the response functions reported by Maier-Reimer and Hasselmann (1987). Interestingly, this non-linear effect is very poorly represented in the IAMs. Only the MAGICC-4 and IMAGE models (that uses the ocean component of the BernCC carbon cycle model (Joos et al. 1996)) show a similar behaviour (although somewhat reduced in MAGICC-4). In almost all other IAMs, the rate of decay is more-or-less similar in both experiments. In default PAGE mode (COU, i.e. with climate-carbon cycle feedback) the rate of decay in fact increases at higher concentrations as a result of the climate feedback (in the version without any feedback, the rate is independent of the concentration). Interestingly, both MERGE and FUND are based on a single 

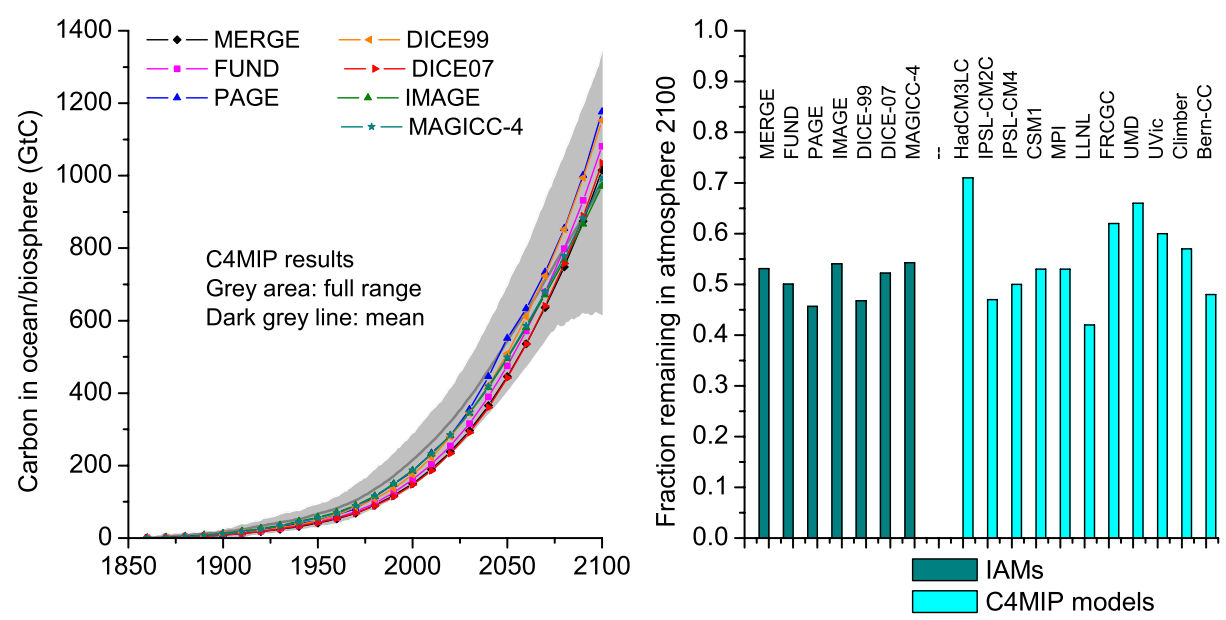

Fig. 7 Fate of emissions under standardized emission scenario (A2); carbon in ocean/biosphere pools (left) and in atmosphere (right). Results for climate models from Friedlingstein et al. (2006) (coupled runs only)

pulse function of Maier-Reimer and Hasselmann (1987) and therefore, their response to concentration is by definition linear.

In addition to the rate of removal in response to emission pulses, we can also look at the fate of $\mathrm{CO}_{2}$ emissions for more policy relevant emissions profiles: Fig. 7 shows the fate of carbon dioxide emissions for the SRES A2 emissions profile (experiment d, see also Fig. 1 and Section 4.6). Carbon emissions finally end up in the atmosphere, the ocean or the terrestrial biosphere. To allow inclusion of even the simplest models in our comparison, however, we need to distinguish only the atmosphere and the other two reservoirs. ${ }^{3}$ These results of the removal under the A2 emission profile can be directly compared to the complex models included in the C4MIP model comparison study (Friedlingstein et al. 2006). Figure 7 shows that the IAMs all lead to a carbon storage fraction in the atmosphere within the range of the complex models, though somewhat at the low end for most of the century. By the end of the century, however, this is not the case any more, as some of the C4MIP models have a relatively strong feedback from temperature on the carbon cycle (see below).

\subsection{How does the climate-carbon cycle feedback behave in IAMs?}

The carbon cycle response depends not only on the atmospheric $\mathrm{CO}_{2}$ concentration, but also on climate feedbacks through temperature and precipitation changes. As shown by Friedlingstein et al. (2006), these impacts on the carbon cycle can be very substantial. In general, they decrease the net absorption of $\mathrm{CO}_{2}$ by the ocean and (for all models included in the C4MIP study) the terrestrial biosphere in simulations where climate change is accounted for compared to simulations where climate is kept constant. The terrestrial biosphere even becomes a source in some models over the

\footnotetext{
${ }^{3}$ The additional carbon in the ocean/biosphere pools can be determined by subtracting the additional carbon remaining in the atmosphere from the total cumulative emissions.
} 
course of the twenty-first century (Cox et al. 2000; Dufresne et al. 2002; Friedlingstein et al. 2001; Joos et al. 2001). Many IAMs, however, do not include a processbased formulation of the carbon cycle and completely lack a climate feedback. Of the models included here only MAGICC-4, IMAGE, and PAGE include a climate feedback on the carbon cycle. The feedbacks included in IMAGE are already rather complex, as they involve grid-level carbon pools (respiration, decay and growth rates), land-cover (types of biomes) and land-use (agricultural area).

The climate-carbon feedbacks of MAGICC-4, IMAGE and PAGE are studied by running the same experiments as in C4MIP with the carbon cycle being either coupled or uncoupled to the changing climate (Friedlingstein et al. 2006). While the C4MIP experiment used only the SRES A2 emissions scenario, we here carry out the experiment for both the high A2 emission pathway and a mitigation pathway (E1) in both cases considering solely the $\mathrm{CO}_{2}$ emissions (see Fig. 1; and also Section 4.6 and Section 4.7 for a complete discussion of the results of these scenarios). As no ESM data are currently available for the E1 scenario, we instead use the results of HadSCCC1 and MAGICC-6, which has been calibrated to the C4MIP models (see Appendix A).

Figure 8 shows the climate-carbon feedback for the IAMs and compares them to the C4MIP results. The climate-carbon cycle feedback is usually computed as the difference of a simulation in which the carbon cycle was allowed to respond to both changes in atmospheric $\mathrm{CO}_{2}$ concentration and climate change (the coupled run; $\mathrm{COU})$, and a second simulation in which the carbon cycle model only experienced the $\mathrm{CO}_{2}$ concentration increases (the uncoupled run; UNC).

In PAGE, all feedbacks (ocean and vegetation) are represented by an aggregated equation that relates a natural emission term (instead of uptake) to temperature. This includes changes in ocean take-up. The emission term is calibrated to results in IPCC's Third Assessment Report and is assumed to be linear to temperature. For the A2 run, the mean PAGE numbers are well within the C4MIP range. For E1, however, the feedback also increases over time and seems to be much larger than in the HadSCCC1 model. The feedback results in mean concentrations from
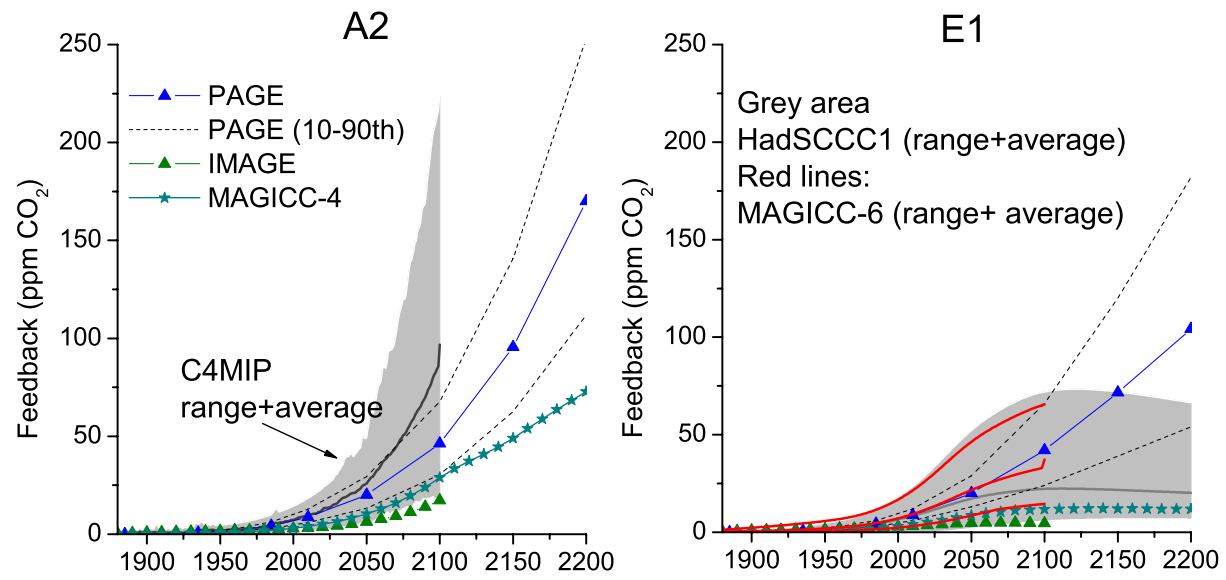

Fig. 8 Temperature feedback on the carbon cycle measured as the difference in $\mathrm{CO}_{2}$ concentration in the coupled and uncoupled run for the A2 (left) and the E1 scenario (right). Climate model results (in grey) are from Friedlingstein et al. (2006) 
the PAGE model continuing to increase even after anthropogenic emissions remain constant in 2100. The MAGICC-4 response is on the low side of the range drawn by the models included in the C4MIP exercise and the HadSCCCM1/MAGICC-6 representation of this range for the E1 scenario (obviously, the MAGICC-4 model was calibrated before the C4MIP experiments were run). Unlike the other models (even HadSCCCM1), the IMAGE carbon cycle model is determined by the grid cells representation of the carbon cycle driven by local temperature and precipitation change (with different impacts in the tropical and temperate zone). The net feedback reported is at the very low end (if at all within) the C4MIP range. The positive feedback of temperature on soil respiration, leading to less soil carbon in the coupled run (and a higher atmospheric concentration) is largely compensated by the positive effect of climate change on net primary production, and by net expansion of highbiomass biomes, e.g. spreading of boreal forest in former tundra regions (leading to a lower concentration). Earlier sensitivity runs, in which the migration of biomes was switched off, showed a $30 \mathrm{ppm}$ higher $\mathrm{CO}_{2}$ concentration (Leemans et al. 2002). A more recent comparison of complex models including dynamic vegetation schemes ${ }^{4}$ shows that these models do not systematically differ from models without dynamic vegetation schemes, but that the uncertainties with regard to the projected climate are substantial (Sitch et al. 2008).

\subsection{Results for high $\mathrm{CO}_{2}$ emissions scenario (C4MIP experiment, A2)}

The A2 scenario is a scenario with relatively high $\mathrm{CO}_{2}$ emissions and has been commonly used to compare results of complex climate models. We use this scenario here to compare the total behaviour of IAMs to the results obtained in the C4MIP experiment (Friedlingstein et al. 2006).

The results show that in 2100 the differences in $\mathrm{CO}_{2}$ concentration are about 100 ppm across the different IAMs (Fig. 9). This is well within the C4MIP range, but still is substantial enough to matter for decision-making. After 2100, the outcomes of the different models further diverge, with the DICE model lying at the low end and MAGICC-4 at the high end. These results can be understood on the basis of the results described in the previous experiments. It should be noted that the IAMs do not necessarily reproduce the historic increase in $\mathrm{CO}_{2}$ concentration between 1860 and 2000 correctly (especially MERGE and FUND, using the Maier-Hasselmann response functions, simulate too high concentration levels). The DICE99 model shows the lowest concentrations, consistent with rapid removal rates reported earlier.

Obviously, the radiative forcing results reflect the differences in concentration levels although some differences occur as a result of the different model-specific values for radiative forcing assumed under a doubling of the $\mathrm{CO}_{2}$ concentration (see Fig. 5 and Section 4.3).

For temperature, all IAMs follow a trajectory in the centre of the C4MIP range. Temperature change is highest for those models that have updated the climate

\footnotetext{
${ }^{4}$ In climate models, land cover is often taken as constant. Dynamic global vegetation models (DGVMs), in contrast, simulate the global distribution of biomes or plant functional types on the basis of factors such as $\mathrm{CO}_{2}$ concentration, climate and soil data. Obviously, change in vegetations (e.g. from a type with a low carbon pool to one with a high carbon pool) could strongly influence the terrestrial carbon uptake.
} 

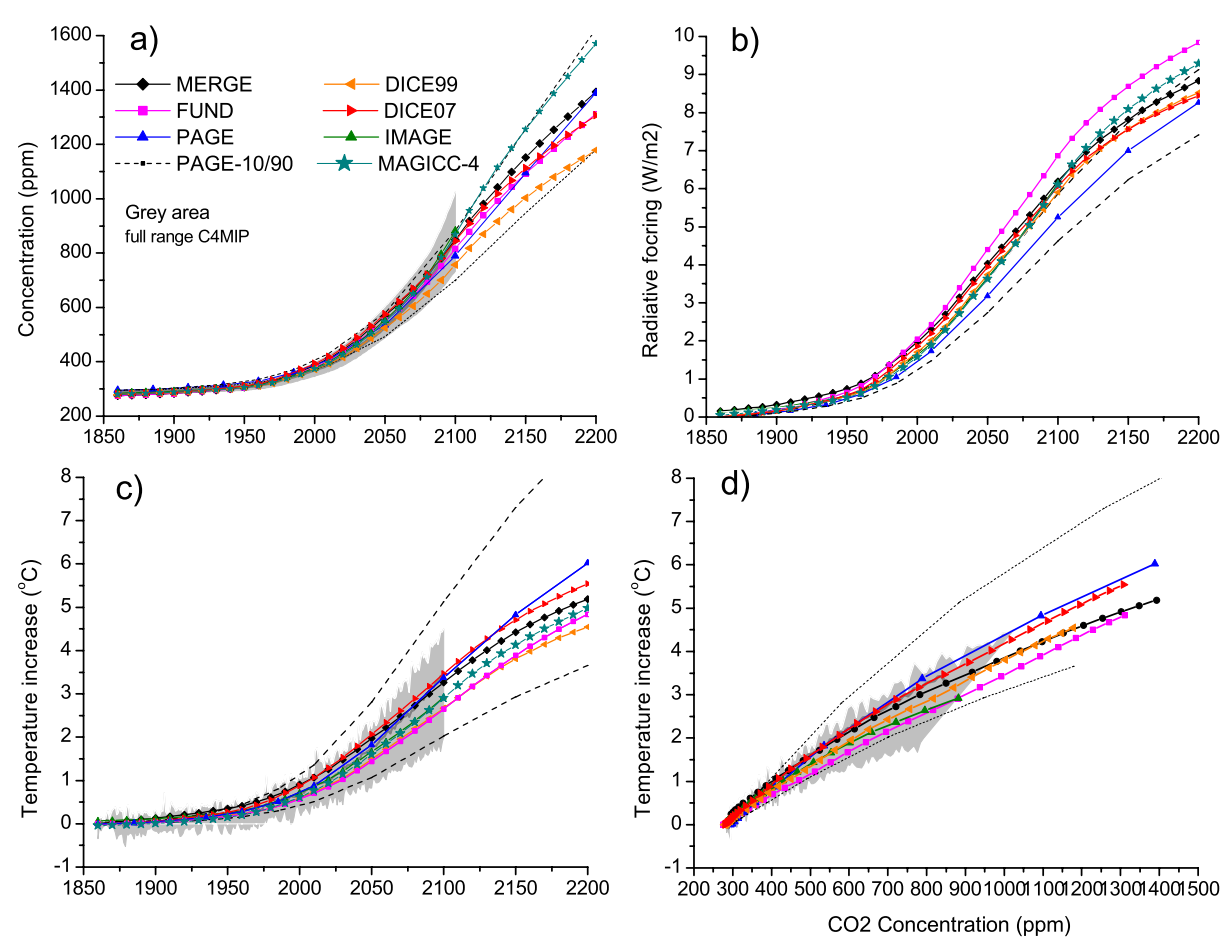

Fig. 9 Results for the A2 emission scenario: a $\mathrm{CO}_{2}$ concentration, b radiative forcing, $\mathbf{c}$ temperature increase, and $\mathbf{d}$ temperature increase versus $\mathrm{CO}_{2}$ concentration. Climate model results from Friedlingstein et al. (2006)

sensitivity to $3^{\circ} \mathrm{C}$ (DICE07) or use a range of climate sensitivities with a mean value of $3^{\circ} \mathrm{C}$ (PAGE). The lowest values are found for DICE99 and FUND, as a result of a rapid $\mathrm{CO}_{2}$ removal rate (DICE) and a slow temperature response (FUND), respectively. The lower right panel illustrates the transient temperature response in the IAMs and the C4MIP models under the A2 scenario. Although Fig. 4 indicated that the transient temperature response under prescribed concentration agreed well between IAMs and C4MIP models. However, as the $\mathrm{CO}_{2}$ concentration is on the high end for the A2 emission pathway for most of the century (upper left panel), the temperature-concentration response is also on the high end.

\subsection{Results for low $\mathrm{CO}_{2}$ emissions scenario E1}

We have also compared the outcomes of the IAMs for the stringent emission reduction scenario E1, an overshoot scenario developed by the IMAGE model to stabilise radiative forcing at $2.6 \mathrm{~W} / \mathrm{m}^{2}$ (see Section 2). For such a scenario, crucial questions are how much temperature increase can be avoided and how reversible the carbon-climate system is. While such low scenarios have been developed in the past using IAMs, results from similar scenarios are not available from AOGCMs or ESMs (some results from EMIC and more comprehensive SCM are available (Friedlingstein 2008; Lowe et al. 2009b; Matthews and Caldeira 2008; Meinshausen 
et al. 2009; Mignone et al. 2008; Nusbaumer and Matsumoto 2008; Solomon et al. 2009; Van Vuuren et al. 2008)). Again, we use the results of HadSCCCM1 and MAGICC-6 (see Appendix A).

The results of the E1 experiment are mostly consistent with those of the SRES A2 experiment (Fig. 10). For $\mathrm{CO}_{2}$ concentrations, in general, the order of the IAMs remains the same. However, there are also differences: while MAGICC-4 results in a relatively high $\mathrm{CO}_{2}$ concentration in the SRES A2 experiment, the model has a relatively low concentration here, although still within expert model ranges. The mean result of the PAGE model has a rather different behaviour than the other models as a result of the strong carbon cycle feedback reported earlier (around a 50 ppm higher $\mathrm{CO}_{2}$ concentration in 2100).

Except for PAGE, all other IAMs show that trends in $\mathrm{CO}_{2}$ concentrations and even temperature can be reversed to some degree in response to declining emissions. This situation would allow for overshoot strategies that lead to limiting climate change while avoiding some of the early reductions (den Elzen and Van Vuuren 2007; Frame et al. 2005; Wigley 2004) -although the slower $\mathrm{CO}_{2}$ removal processes will also provide some limitations (Solomon et al. 2009). In the results of the IAM models, the $\mathrm{CO}_{2}$ concentrations peak around 2050 and then decline to levels between 350 and $400 \mathrm{ppm}$ in 2200, in most models. At the moment, hardly any runs exist with more complex carbon cycle and climate models that explore the dynamics in
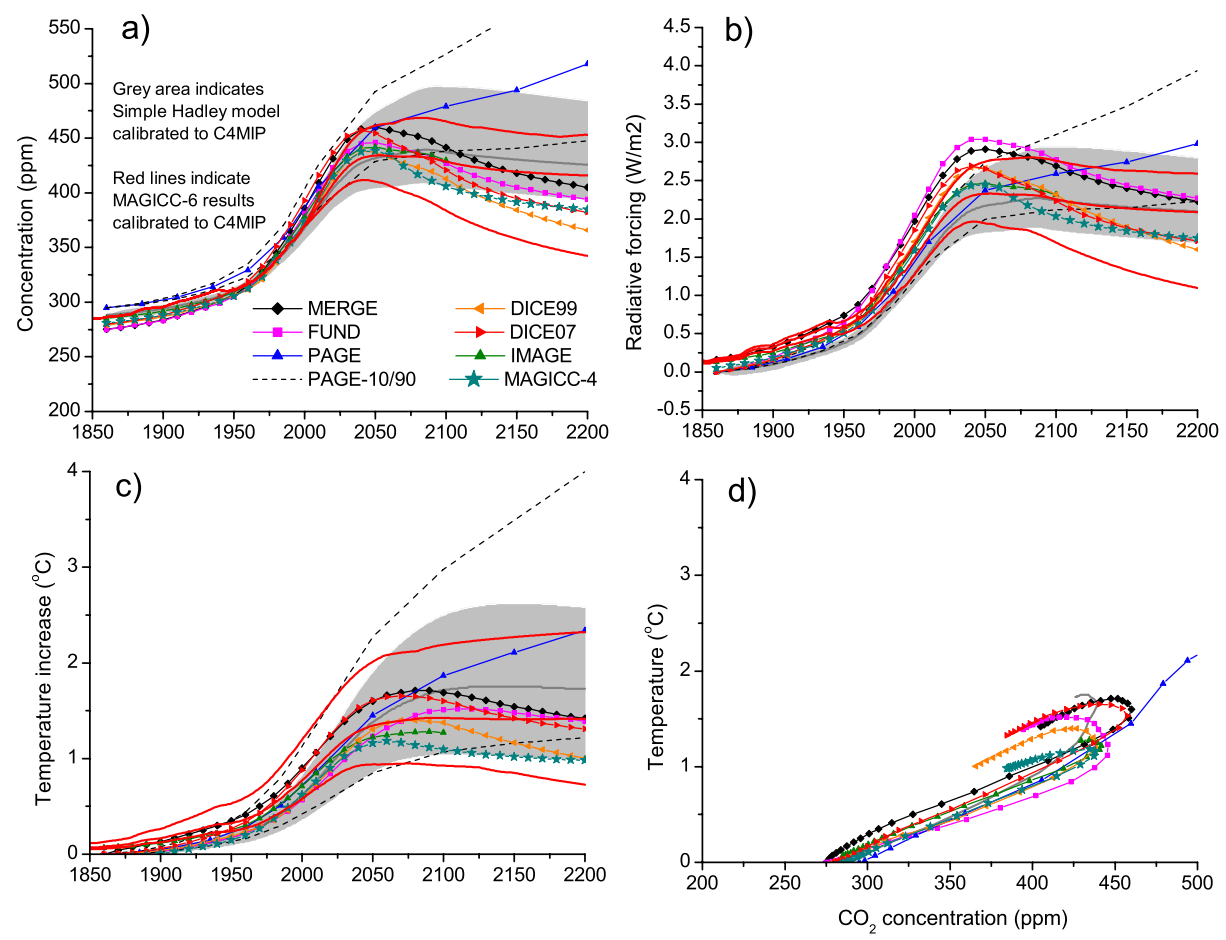

Fig. 10 Results for the E1 scenario: $\mathbf{a ~} \mathrm{CO}_{2}$ concentration, $\mathbf{b}$ radiative forcing, $\mathbf{c}$ temperature increase, and $\mathbf{d}$ temperature increase versus $\mathrm{CO}_{2}$ concentration. Shaded area indicates results of HadSCCCM1; red lines those of MAGICC-6 (90th percentile and mean) 
these models in response to overshoot strategies. The available runs from EMICs or other publications show a wide range of results or expectations for the timing of peak concentration, carbon budgets for different concentration levels or the reversibility of $\mathrm{CO}_{2}$ concentration levels (see earlier references). The two models used here as reference also show different behaviour. The HadSCCCM1 model shows a peak in $\mathrm{CO}_{2}$ concentration but this is much less pronounced than the peak in MAGICC-6 and occurs later. The MAGICC-6 model, which is also calibrated to the C4MIP outcomes, shows a behaviour which is similar to the IAMs. These results emphasise the need for simulations with complex models to tests the behaviour of IAMs for low concentrations and, in particular, overshoot strategies.

For temperature, the results across the IAMs are more comparable and are within the range of outcomes for the HadSCCCM1 and MAGICC-6 models. The temperature increase ranges from 1.0 to 1.9 in 2100 (MAGICC-4 and IMAGE on the low side). In the mean result from the PAGE model, temperature does not stabilise because the concentration does not stabilise.

\section{Discussion and conclusions}

Integrated Assessment Models (IAMs) are a vital tool in informing the debate on future global and national emissions of greenhouse gases and the cost associated with different mitigation options. They consist of economic models coupled to simple climate and carbon cycle models. Here we concentrate on the climate and carbon cycle components of the IAMs, demonstrating how differences in these components can lead to large differences in the climate outcomes. This is very relevant for policymaking, affecting cost-benefit analysis and the assessment of mitigation costs. For instance, in our EMF-21 re-run (putting the emissions from several IAMs into a single SCM) it was shown that differences between the emission profiles of the various models in terms of radiative forcing levels was easily $0.25 \mathrm{~W} / \mathrm{m}^{2}$, corresponding to a difference in $\mathrm{CO}_{2}$ concentration $\left(\right.$ at $4.5 \mathrm{~W} / \mathrm{m}^{2}$ ) of around $30 \mathrm{ppm}$. In terms of emissions, such a difference corresponds to a cumulative emission differences of roughly $100 \mathrm{Gt}$. In other words, this model spread may easily equate to thousands of billion US\$ in terms of cumulative abatement costs (for instance, assuming an average carbon price around $100 \mathrm{US} \$ / \mathrm{tC})$.

IAMs are typically not designed to create new insights on climate science issues; their value is in understanding and projecting the interaction between the climate and the economic system. Therefore, it is reasonable to expect the response of IAM climate and carbon cycle components to be within the range of outcomes of sophisticated, state-of-the-art climate models or comprehensive terrestrial/oceanic ecosystem-biogeochemistry models. In fact, one may argue that IAMs should in their default settings represent the mean outcomes of these models, while exploring the total range in uncertainty analyses.

We have devised a set of IAM experiments that quantify the magnitude and timescale of warming to a given forcing. We have also examined the time-scales of removal of atmospheric $\mathrm{CO}_{2}$ in the models and the size of climate feedbacks on the carbon cycle. Because many of these experiments have been performed with more complex climate and carbon cycle models previously, we can compare the IAMs behaviour with those models. Where scenarios have not yet been available, we 
compare the IAMs to "expert" climate models. While these both have the limitations of being much less complex than GCMs or three dimensional earth system models, they are more complex than many of the IAMs climate and carbon cycle components and, more importantly, both have demonstrated skill in emulating a range of complex earth system models.

For the model simulations presented in this paper, the representations of the carbon cycle and climate system in IAMs mostly lie within the range of expert models. These ranges are, however, often very wide and consequently, the differences in carbon cycle and climate system representation play a significant role in their outcomes (in addition to uncertainty in socio-economic components). It is useful to discuss the details of the IAM response. We will consider the cause-to-effect chain, starting with the temperature response then working back through forcing and carbon cycle issues.

Thermal response The default setting of the climate sensitivity of most IAMs (e.g. MERGE, IMAGE, MAGICC-4) is still calibrated to the values reported in the IPCC's Third Assessment Report and our first recommendation is that these should be updated to the Fourth Assessment Report (e.g. with respect to the mean value). The newer IPCC report includes a larger number of climate sensitivity estimates and updates the likely ranges of climate sensitivity. It also presents evidence of complex models with large climate sensitivity beyond the often used upper value of $4.5^{\circ} \mathrm{C}$. Figure 3 clearly shows a bias of the IAMs towards the lower end of the likely AR4 range; only PAGE samples this range by default. The implication of most IAMs not sampling the upper part of the IPCC AR4 range of likely climate sensitivities is that in the long-term the larger damages associated with these higher temperature ranges are not being simulated.

In addition to equilibrium climate change, also transient climate change is important for IAM outcomes. For transient climate change, ocean heat uptake is also important. Figure 3 shows a wide spread in transient responses for our IAMs, with FUND and PAGE (mean) being notably slow. In the $2 \times \mathrm{CO}_{2}$ experiment (Fig. 4 ) the DICE99 shows an initially slow response as well. An implication of a slow thermal response is that if these models are used for cost-benefit analysis, impacts occur later in time (or even outside the simulation period) and thus are affected more by discounting than would be the case if median values were used. It also has impacts for the study of overshoot scenarios, with a slower thermal response permitting a longer period of concentration overshooting before the temperature exceeds its target level.

Forcing response The next step in the cause-to-effect chain is the relationship between $\mathrm{CO}_{2}$ concentration in the atmosphere and radiative forcing. There is a significant spread in the IAM results, reaching around $1 \mathrm{~W} \mathrm{~m}^{-2}$ at around $750 \mathrm{ppm}$. The difference is partly caused by the use of older values for $\mathrm{CO}_{2}$ forcing. FUND has the largest forcing for a given concentration and PAGE has the lowest, implying that for a given $\mathrm{CO}_{2}$ concentration the difference in equilibrium temperature response between FUND and the mean results from PAGE will be less than implied by the climate sensitivity alone. The difference in concentration-forcing relationship also leads to different implications of radiative forcing (and $\mathrm{CO}_{2}$-equivalent concentrations) targets. For instance, for a target of $4.5 \mathrm{~W} \mathrm{~m}^{-2}$ there is a spread of $0.7 \mathrm{~W} / \mathrm{m}^{2}$ corresponding to $\sim 100 \mathrm{ppm} \mathrm{CO}_{2}$, with FUND requiring the lowest concentrations. 
The implications of this for the necessary emissions to reach a given forcing target were clearly seen in the EMF-21 rerun results.

Carbon cycle response The carbon cycle component in the IAM determines the $\mathrm{CO}_{2}$ concentration for a given set of emissions. First, we note that there is agreement between the proportion of a carbon pulse that stays in the atmosphere on time scales of less than two decades but the spread increases beyond this time. Apart from the PAGE model, the IAMs show that between $10 \%$ and $25 \%$ of the carbon pulse remains in the atmosphere after around 300 years, which can be compared to the expert Bern $2.5 \mathrm{CC}$ model values of around $20 \%$. The lowest IAM values are seen in the two versions of the DICE model, which tend to remove carbon from the atmosphere too quickly. A consequence is that climate impacts of non-intervention scenarios could be higher than suggested by these models, but also that it might be more difficult to achieve very low concentration targets. The PAGE response is the most unusual, showing that the mean results would lose about $50 \%$ of the initial pulse after 50 years (still fairly consistent with the other IAMs and the Bern2.5CC expert models) but, because of the strong carbon cycle feedback, unlike all of the other models, the proportion starts to increase again at later times, reaching a carbon concentration in the atmosphere of $70 \%$ of the initial value after 300 years. This implies that in PAGE a unit of carbon emission into the atmosphere will lead to a higher atmospheric concentration of $\mathrm{CO}_{2}$ several hundred years later than other IAMs. Compared to the more complex models, PAGE predicts more climate change for low emissions.

Many of the processes in the carbon cycle are known to be non-linear. Expert carbon cycle models show a higher airborne fraction at a given time for a larger emissions pulse. This behaviour is also replicated in MAGICC-4 and IMAGE, but is simply not included in other IAMs (that assume a linear relationship). The PAGE mean version behaves in the opposite manner to expectations, because of its strong carbon cycle feedback.

The feedback of climate change onto the carbon cycle is a topic of current scientific debate. Some IAMs do not include this feedback and those IAMs that do include this feedback show substantially different strengths. For high concentrations, the variation is more or less within the very wide range of the C4MIP models, varying from a very low feedback in IMAGE to a strong feedback in the mean results from PAGE. At low concentrations, the feedback cannot be directly evaluated against complex climate models as they have not been run for these targets yet. The dynamics of the climate-carbon feedback might be different under such scenarios, especially as the large thermal inertia of the climate system means that temperatures can continue to increase, while $\mathrm{CO}_{2}$ concentrations are already in decline. The IAM results show a far wider range than the expert simple climate models (calibrated to the C4MIP GCMs), with the IMAGE model having a very small feedback (possibly from the dynamic representation of natural vegetation) and the mean results of PAGE showing a very strong feedback that can easily be strong enough to lead to higher concentrations levels.

All factors together: high and low $\mathrm{CO}_{2}$ emission scenarios (A2/E1) The behaviour of the IAMs for the high $\mathrm{CO}_{2}$ emission scenario can be explained on the basis of the behaviour of the model components discussed above. There are noticeable 
differences between the IAMs but the overall representation of a high emission scenario in IAMs is easily within the range of the complex models.

The relative differences for the low $\mathrm{CO}_{2}$ emission scenario across the different IAMs are larger than for the high emission scenario. Still, with the exception of PAGE, all models show a decline in radiative forcing and even temperature for a rapid decline in emissions. The results for a low concentration scenario cannot be directly compared to complex climate models. At this stage, low stabilisation targets and overshoot scenarios have only been run using IAMs and (to a lesser degree) EMICs. There is a clear need for more complex models to run low mitigation scenarios to learn more about the behaviour of the carbon cycle and climate system under these conditions which are directly relevant for policy-making. The very different outcomes of "C4-MIP" calibrated models for low stabilisation scenarios (MAGICC-6, HadSCCCM1 and MAGICC-4) is illustrative of the lack of insight in the different processes (and the reversibility of $\mathrm{CO}_{2}$ concentration levels) in these situations.

Recommendations for the IAM and climate communities Most of the short-comings in IAM climate and carbon cycle responses mentioned above can be handled relatively easily by updating their parameter settings. We recommend doing this as a priority task. For the biophysical impact models, further incorporation of complex carbon cycle and climate change representations by including parts of models like MAGICC-6, HadSCCCM1 or Bern2.5CC might be attractive. However, for costbenefit-analysis-type of IAMs, this is a complex challenge as these models need a simpler representation of the carbon cycle/climate system to allow inter-temporal optimisation.

Given the uncertainty in climate feedback onto the carbon cycle, we recommend that IAMs should consider including these feedbacks in their uncertainty analysis. Our results also suggests a very pressing need for the climate modelling community to run their more complex earth system models for scenarios with aggressive mitigation and lower emissions than the IPCC SRES range, including scenarios where the concentration overshoots the eventual target level. This is because even the expert simple climate models can not hope to capture the complex geographical nature of carbon cycle changes and local feedbacks, such as those involving local hydrology changes which are believed to have a significant interaction with local vegetation. The forthcoming IPCC AR5 assessment will involve such ESM simulations, but it is important these are made available to the IAM community as early as possible.

Finally, it is vital that policy makers, especially those involved in UNFCCC negotiations, are made aware of the large spread in the climate and earth system components of IAMs. More work is recommended to understand how these affect the economic outputs from current IAMs.

\section{Appendix A}

In this article, we compare the behavior of the IAM models against available data from complex models (including the ranges across these models). Unfortunately, for some experiments these data are not directly available. Here, we have used the results of specific simulations from models with a somewhat more comprehensive 

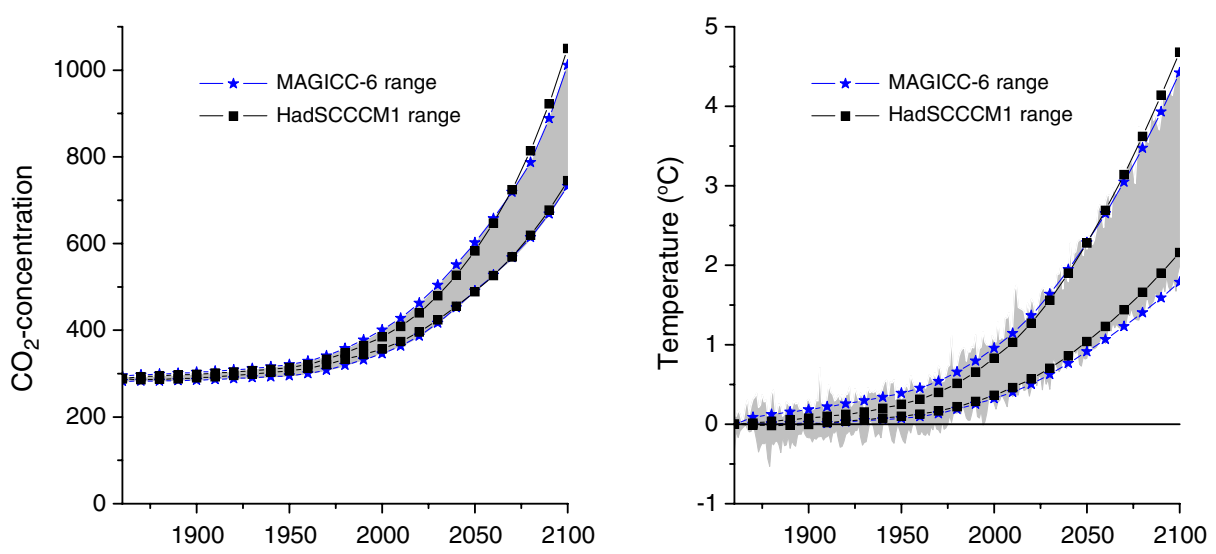

Fig. 11 Results for the A2 experiment. Range of results of the MAGICC-6 and HadSCCCM1 models compared to the range of the original C4MIP outcomes (grey area)

representation of the climate system and carbon cycle: the Bern 2.5CC EMIC (Plattner et al. 2008), the HadSCCCM1 (Huntingford et al. 2009) and MAGICC-6 (Meinshausen et al. 2008) models. The last two models are both calibrated against the results of more complex models using the C4MIP data. Both models aim to represent individual models in the C4MIP exercise for a A2 scenario (i.e. a high emission scenario). This arguably allows us to get some idea how more complex models would perform if run under different assumptions such as a low emission scenario. In order to provide a meaningful reference, it is obviously at least necessary that these expert models indeed represent the original C4MIP data well.

In Fig. 11, we show the original C4MIP outcomes and the MAGICC-6 and HadSCCCM1 representation of them (i.e. the lowest and highest result). The figure shows that both models are indeed able to reproduce the C4MIP range well. This is certainly the case for the $\mathrm{CO}_{2}$ concentration. For temperature, the simple models obviously do not represent the variation included in the complex models, and the HadSCCCM1 has a slight bias to higher temperatures late in the experiment. As discussed in the main text, the fact that both models reproduce the A2 results does not automatically mean that they lead to the same results under different conditions. The fact that MAGICC-6 and HadSCCCM1 lead to different results for a low emission scenario shows that this not the case (Fig. 10).

\section{References}

Bouwman L, Kram T, Klein-Goldewijk K (2006) Integrated modelling of global environmental change. An overview of IMAGE 2.4. The Netherlands Environmental Assessment Agency, Bilthoven

Cox PM, Betts RA, Jones CD, Spall SA, Totterdell IJ (2000) Acceleration of global warming due to carbon-cycle feedbacks in a coupled climate model. Nature 408:180-184

den Elzen MGJ, Van Vuuren DP (2007) Peaking profiles for achieving long-term temperature targets with more likelihood at lower costs. Proc Natl Acad Sci U S A 104:17931-17936 
Dufresne J-L, Friedlingstein P, Berthelot M, Bopp L, Ciais P, Fairhead L, Monfray P (2002) Effects of climate change due to $\mathrm{CO}_{2}$ increase on land and ocean carbon uptake. Geophys Res Lett 29:1405

Edmonds JA, Clarke J, Dooley J, Kim SH, Smith SJ (2004) Modelling greenhouse gas energy technology responses to climate change. Energy 29:1529-1536

Eickhout B, Den Elzen MG, Kreileman GJJ (2004) The atmosphere-ocean system of IMAGE 2.2. National Institute for Public Health and the Environment, Bilthoven

Frame DJ, Booth BBB, Kettleborough JA, Stainforth DA, Gregory JM, Collins M, Allan MR (2005) Constraining climate forecasts: the role of prior assumptions. Geophys Res Lett 32:L09702

Friedlingstein P (2008) A steep road to climate stabilization. Nature 451:297-298

Friedlingstein P, Bopp L, Ciais P, Dufresne J-L, Fairhead L, LeTreut H, Monfray P, Orr J (2001) Positive feedback between future climate change and the carbon cycle. Geophys Res Lett 28:1543-1546

Friedlingstein P, Cox P, Betts R, Bopp I, Von bloh W, Brovkin V, Cadule P, Doney S, Eby M, Fung I, Bala G, John J, Jones C, Joos F, Kato T, Kawamiya M, Knorr W, Lindsay K, Matthews HD, Raddatz T, Rayner P, Reick C, Roeckner E, Schnitzler KG, Schnur R, Strassmann K, Weaver AJ, Yoshikawa C, Zeng N (2006) Climate-carbon cycle feedback analysis: results from the C4MIP model intercomparison. J Clim 19:3337-3353

Füssel HM (2007) Methodological and empirical flaws in the design and application of simple climate-economy models. Clim Change 81:161-185

Goodess CM, Hanson C, Hulme M, Osborn TJ (2003) Representing climate and extreme weather events in integrated assessment models: a review of existing methods and options for development. Integr Assess 4:145-171

Häfele W, Anderer JAM, Nakicenovic N (1981) Energy in a finite world. Ballinger, Cambridge

Harremoes P, Turner RK (2001) Methods for integrated assessment. Reg Environ Change 2:57-65

Hof AF, den Elzen MGJ, van Vuuren DP (2008) Analysing the costs and benefits of climate policy: value judgements and scientific uncertainties. Glob Environ Change 18:412-424

Hooss G, Voss R, Hasselmann K, Joos F (2001) A nonlinear impulse response model of the coupled carbon cycle-climate system (NICCS). Clim Dyn 18:189-202

Hope C (2005) Integrated assessment models. In: Helm D (ed) Climate change policy. Oxford University Press, Oxford

Hope C (2006) The marginal impact of CO2 from PAGE2002: an integrated assessment model incorporating the IPCC's five reasons for concern. Integr Assess 6:19-56

Huntingford C, Lowe J (2007) "Overshoot" scenarios and climate change. Science 316:829

Huntingford C, Lowe JA, Booth BBB, Jones CD, Harris GR, Gohar LK, Meir P (2009) Contributions of carbon cycle uncertainty to future climate projection spread. Tellus Ser B Chem Phys Meteorol 61:355-360

IPCC (2001) Climate change 2001. In: Third assessment report of the intergovernmental panel on climate change. Cambridge University Press, Cambridge

Joos F, Bruno M, Fink R, Siegenthaler U, Stocker TF, Le Quéré C, Sarmiento JL (1996) An efficient and accurate representation of complex oceanic and biospheric models of anthropogeninic carbon uptake. Tellus 48B:397-417

Joos F, Müller-Fürstenberger G, Stephan G (1999) Correcting the carbon cycle representation: how important is it for the economics of climate change? Environ Model Assess 4:133-140

Joos F, Prentice C, Sitch S, Meyer R, Hooss G, Plattner G-K, Gerber S, Hasselmann K (2001) Global warming feedbacks on terrestrial carbon uptake under the Intergovernmental Panel on Climate Change (IPCC) emission scenarios. Glob Biogeochem Cycles 15:891-907

Lashof DA, Tirpack DA (1989) Policy options for stabilising global climate. US Environmental Protection Agency, Washington

Leemans R, Eickhout B, Strengers BJ, Bouwman AF, Schaefer M (2002) The consequences for the terrestrial carbon cycle of uncertainties in land use, climate and vegetation responses in the IPCC SRES scenarios. Sci China Ser C 45:126-136

Lowe JA, Hewitt CD, Van Vuuren DP, Johns TC, Stehfest E, Royer J-F, van der Linden PJ (2009a) Will aggressive mitigation of emissions really avoid dangerous climate change? EOS 90:181-188

Lowe JA, Huntingford C, Raper SCB, Jones CD, Liddicoat SK, Gohar LK (2009b) How difficult is it to recover from dangerous levels of global warming? Environ Res Netw 4:1-9

Maier-Reimer E, Hasselmann K (1987) Transport and storage of carbon dioxide in the ocean: an inorganic ocean circulation carbon cycle model. Clim Dyn 2:63-90

Manne AS, Richels RG (2005) Merge: an integrated assessment model for global climate change. In: Loulou R, Waaub J-P, Zaccour G (eds) Energy and environment. Springer, New York 
Matthews HD, Caldeira K (2008) Stabilizing climate requires near-zero emissions. Geophys Res Lett 35:L04705

Meehl GA, Stocker TF, Collins WD, Friedlingstein P, Gaye AT, Gregory JM, Kitoh A, Knutti R, Murphy JM, Noda A, Raper SCB, Watterson IG, Weaver AJ, Zhao Z-C (2007) Global climate projections. In: Solomon S, Qin D, Manning M, Chen Z, Marquis M, Averyt KB, Tignor M, Miller HL (eds) Climate change 2007: the physical science basis. Contribution of working group I to the fourth assessment report of the intergovernmental panel on climate change. Cambridge University Press, Cambridge

Meinshausen M, Raper SCB, Wigley TML (2008) Emulating IPCC AR4 atmosphere-ocean and carbon cycle models for projecting global-mean, hemispheric and land/ocean temperatures: MAGICC 6.0. Atmos Chem Phys Discuss 8:6153-6272

Meinshausen M, Meinshausen N, Hare B, Raper SCB, Frieler K, Knutti R, Frame DJ, Allen MR (2009) Greenhouse-gas emission targets for limiting global warming to $2^{\circ} \mathrm{C}$. Nature $458: 1158-$ 1162

Mignone BK, Socolow RH, Sarmiento JL, Oppenheimer M (2008) Atmospheric stabilization and the timing of carbon mitigation. Clim Change 88:251-265

Mintzer I (1987) A matter of degrees: the potential for controlling the greenhouse effect. World Resources Institute, Washington

Moss R, Babiker M, Brinkman S, Calvo E, Carter T, Edmonds J, Elgizouli I, Emori S, Erda L, Hibbard KA, Jones R, Kainuma M, Kelleher J, Lamarque JF, Manning M, Matthews B, Meehl J, Meyer L, Mitchell J, Nakicenovic N, O’Neill B, Pichs R, Riahi K, Rose S, Runci P, Stouffer RJ, van Vuuren D, Weyant J, Wilbanks T, van Ypersele JP, Zurek M (2008) Towards new scenarios for analysis of emissions, climate change, impacts, and response strategies. IPCC Expert Meeting Report on New Scenarios. Intergovernmental Panel on Climate Change, Noordwijkerhout

Murphy JM, Sexton DMH, Barnett DN, Jones GS, Webb MJ, Collins M, Stainforth DA (2004) Quantification of modelling uncertainties in a large ensemble of climate change simulations. Nature 430:768-772

Nakicenovic (2000) Special Report on Emissions Scenarios (SRES). Cambridge University Press, Cambridge, UK

Nordhaus WD (1979) The efficient use of energy resources. Yale University Press, New Haven

Nordhaus WD (2008) A question of balance weighing the options on global warming policies. Yale University Press, New Haven

Nordhaus WD, Boyer J (1999) Roll the DICE again: the economics of global warming. Yale University, New Haven

Nusbaumer J, Matsumoto K (2008) Climate and carbon cycle changes under the overshoot scenario. Glob Planet Change 62:164-172

Plattner GK, Knutti R, Joos F, Stocker TF, von Bloh W, Brovkin V, Cameron D, Driesschaert E, Dutkiewicz S, Eby M, Edwards NR, Fichefet T, Hargreaves JC, Jones CD, Loutre MF, Matthews HD, Mouchet A, Müller SA, Nawrath S, Price A, Sokolov A, Strassmann KM, Weaver AJ (2008) Long-term climate commitments projected with climate-carbon cycle models. J Clim 21:27212751

Ramaswamy V (2001) Radiative forcing of climate change. In: JT H, Ding Y, Griggs DJ, Noguer M, van der Linden PJ, Dai X, Maskell K, Johnson CA (eds) Climate change 2001: the scientific basis. Cambridge University Press, Cambridge

Randall DA, Wood RA, Bony S, Colman R, Fichefet T, Fyfe J, Kattsov V, Pitman A, Shukla J, Srinivasan J, Stouffer RJ, Sumi A, Taylor KE (2007) Climate models and their evaluation. In: Solomon S, Qin D, Manning M, Chen Z, Marquis M, Averyt KB, Tignor M, Miller HL (eds) Climate change 2007: the physical science basis. Contribution of working group I to the fourth assessment report of the intergovernmental panel on climate change. Cambridge University Press, Cambridge

Revelle R, Suess H (1957) Carbon dioxide exchange between atmosphere and ocean and the question of an increase of atmospheric $\mathrm{CO}_{2}$ during the past decades. Tellus 9:18

Riahi K, Gruebler A, Nakicenovic N (2007) Scenarios of long-term socio-economic and environmental development under climate stabilization. Technol Forecast Soc Change 74:887-935

Rotmans J, de Boois H, Swart RJ (1990) An integrated model for the assessment of the greenhouse effect: the Dutch approach. Clim Change 16:331-356

Schimel DS (1998) The carbon equation. Nature 393:208-209

Schneider SH (1997) Integrated assessment modeling of global climate change: transparent rational tool for policy making and opaque screen hiding value-laden assumptions? Environ Model Assess 2:229-249 
Schneider SH, Thompson SL (1981) Atmospheric $\mathrm{CO}_{2}$ and climate: Importance of the transient response. J Geophys Res 86:3135-3147

Schultz PA, Kasting JF (1997) Optimal reductions in $\mathrm{CO}_{2}$ emissions. Energy Policy 25:491-500

Shine KP, Derwent RG, Wuebbles DJ, Morcrette J-J (1990) Greenhouse gases and aerosols. In: Houghton JT, Jenkins GJ, Ephraums JJ (eds) Climate change: the IPCC scientific assessment. Cambridge University Press, Cambridge

Sitch S, Huntingford C, Gedney N, Levy PE, Lomas M, Piao SL, Betts R, Ciais P, Cox P, Friedlingstein P, Jones CD, Prentice IC, Woodward FI (2008) Evaluation of the terrestrial carbon cycle, future plant geography and climate-carbon cycle feedbacks using 5 Dynamic Global Vegetation Models (DGVMs). Glob Chang Biol 14:2015-2039

Smith SJ, Edmonds JA (2006) The economic implications of carbon cycle uncertainty. Tellus B 58:586-590

Sokolov AP, Schlosser CA, Dutkiewicz S, Paltsev S, Kicklighter DW, Jacoby HD, Prinn RG, Forest CE, Reilly JM, Wang C, Felzer B, Sarofim MC, Scott J, Stone PH, JM M, Cohen J (2005) The MIT Integrated Global System Model (IGSM) version 2: model description and baseline evaluation. MIT, Cambridge

Solomon S, Plattner GP, Knutti R, Friedlingstein P (2009) Irreversible climate change due to carbon dioxide emissions. Proc Natl Acad Sci U S A 106:1704-1709

Tol RSJ (2006) Multi-gas emission reduction for climate change policy: an application of FUND. Energy J 3:235-250

Van der Sluijs JP (2002) Integrated assessment. In: Munn RE, Tolba M (eds) Encyclopaedia of global environmental change-responding to global environmental change. Wiley, London, pp 250-253

Van Vuuren DP, Weyant J, De la Chesnaye F (2006) Multigas scenarios to stabilise radiative forcing. Energy Econ 28:102-120

Van Vuuren DP, Den Elzen MGJ, Lucas PL, Eickhout B, Strengers BJ, Van Ruijven B, Wonink S, Van Houdt R (2007) Stabilizing greenhouse gas concentrations at low levels: an assessment of reduction strategies and costs. Clim Change 81:119-159

Van Vuuren DP, Meinshausen M, Plattner GK, Joos F, Strassmann KM, Smith SJ, Wigley TML, Raper SCB, Riahi K, De La Chesnaye F, Den Elzen MGJ, Fujino J, Jiang K, Nakicenovic N, Paltsev S, Reilly JM (2008) Temperature increase of 21st century mitigation scenarios. Proc Natl Acad Sci U S A 105:15258-15262

Warren R, de la Nava Santos S, Arnell NW, Bane M, Barker T, Barton C, Ford R, Füssel H-M, Hankin RKS, Klein R, Linstead C, Kohler J, Mitchell TD, Osborn TJ, Pan H, Raper SCB, Riley G, Schellnhüber HJ, Winne S, Anderson D (2008) Development and illustrative outputs of the Community Integrated Assessment System (CIAS), a multi-institutional modular integrated assessment approach for modelling climate change. Environ Model Softw 23:592-610

Weyant J, Davidson O, Dowlatabadi H, Edmonds J, Grubb M, Richels R, Rotmans J, Shukla P, Cline W, Fankhauser S, Tol R (1996) Integrated assessment of climate change: an overview and comparison of approaches and results. In: Bruce JP, Lee H, Haites EF (eds) Climate change 1995-economic and social dimensions of climate change. Contribution of working group III to the second assessment report of the intergovernmental panel on climate change (IPCC). Cambridge University Press, Cambridge

Weyant JP, de la Chesnaye FC, Blanford GJ (2007) Overview of EMF21: multigas mitigation and climate policy. Energy J \#3:1-32

Wigley TML (1993) Balancing the carbon budget. Implications for projections of future carbon dioxide concentration changes. Tellus Ser B Chem Phys Meteorol 45B:409-425

Wigley TML (2004) Overshoot pathways to CO2 concentration stabilization. Workshop on GHG stabilization scenarios, Tsukuba, Japan, 23 Jan 2004

Wigley TML, Raper SCB (2001) Interpretation of high projections for global-mean warming. Science 293:451-454 